\title{
Stage-specific control of oligodendrocyte
}

\section{survival and morphogenesis by TDP-43}

Dongeun $\mathrm{Heo}^{1}$, Jonathan P. Ling ${ }^{1,2}$, Gian C. Molina-Castroํ, Abraham J. Langseth¹, Ari Waisman², Klaus-Armin Nave ${ }^{4}$, Wiebke Möbius ${ }^{4,5,6}$, Philip C. Wong², \& Dwight E. Bergles ${ }^{1,7,}$ *
${ }^{1}$ The Solomon H. Snyder Department of Neuroscience, Johns Hopkins University School of Medicine, Baltimore, MD 21205, USA.

2 Department of Pathology, Johns Hopkins University School of Medicine, Baltimore, MD 21205, USA.

${ }^{3}$ Institute for Molecular Medicine, University Medical Center of the Johannes Gutenberg University, Mainz, Germany.

${ }^{4}$ Department of Neurogenetics, Max Planck Institute of Experimental Medicine, Göttingen, Germany.

${ }^{5}$ Cluster of Excellence "Multiscale Bioimaging: from Molecular Machines to Networks of Excitable Cells" (MBExC), University of Göttingen, Germany.

${ }^{6}$ Electron Microscopy Core Unit, Max-Planck-Institute of Experimental Medicine, Göttingen, Germany.

${ }^{7}$ Kavli Neuroscience Discovery Institute, Johns Hopkins University, Baltimore, MD 21205, USA.

* Correspondence:

Dwight E. Bergles, PhD

Solomon H. Snyder Department of Neuroscience

Johns Hopkins University School of Medicine

725 N. Wolfe Street, Baltimore, MD 21205, USA

$P: 410-955-6939$

dbergles@jhmi.edu 
Abstract

31 Generation of oligodendrocytes in the adult brain enables both adaptive changes in neural circuits and regeneration of myelin sheaths destroyed by injury, disease, and normal aging. This transformation of oligodendrocyte precursor cells (OPCs) into myelinating oligodendrocytes requires processing of distinct mRNAs at different stages of cell maturation. Although mislocalization and aggregation of the RNA binding protein TDP-43 occur in both neurons and glia in neurodegenerative diseases, the consequences of TDP-43 loss within different stages of the oligodendrocyte lineage are not well understood. By performing stagespecific genetic inactivation of Tardbp in vivo, we show that oligodendrocyte lineage cells are differentially sensitive to loss of TDP-43. While OPCs depend on TDP-43 for survival, with conditional deletion resulting in cascading cell loss followed by rapid regeneration to restore their density, oligodendrocytes become less sensitive to TDP-43 depletion as they mature. Deletion of TDP-43 early in the maturation process led to eventual oligodendrocyte degeneration, seizures and premature lethality, while oligodendrocytes that experienced late deletion survived and mice exhibited a normal lifespan. At both stages, TDP-43 deficient oligodendrocytes formed fewer and thinner myelin sheaths and extended new processes that inappropriately wrapped neuronal somata and blood vessels. Transcriptional analysis revealed that in the absence of TDP-43, key proteins involved in oligodendrocyte maturation and myelination were misspliced leading to aberrant incorporation of cryptic exons. Inducible deletion of TDP-43 from oligodendrocytes in the adult CNS induced the same progressive morphological changes and mice acquired profound hindlimb weakness, suggesting that loss of TDP-43 function in oligodendrocytes may contribute to neuronal dysfunction in neurodegenerative disease. 


\section{Introduction}

The distribution of myelin in the adult brain is not static, as new oligodendrocytes continue to be generated in response to changes in experience, such as enhanced sensory input and intense motor learning (Hughes et al. 2018; Xiao et al. 2016). As a result, oligodendrocyte lineage cells exist in a developmental continuum throughout life, consisting of oligodendrocyte precursor cells (OPCs) that maintain their density through proliferation (Hughes et al. 2013), and cells in the process of maturing from premyelinating to myelinating oligodendrocytes. This ongoing oligodendrogenesis is necessary to prolong the period of circuit maturation (Benamer et al. 2020), enable adaptive changes in myelination (Gibson et al. 2014), and restore myelin lost through aging or demyelinating injuries (Orthmann-Murphy et al. 2020; Bacmeister et al. 2020). The transition from progenitor to myelin forming oligodendrocyte requires profound transcriptional changes, in which myelinassociated gene networks are activated and mRNAs are transported to distal processes to direct sites of axon ensheathment and membrane compaction (Müller et al. 2013). These transcriptional and post-transcriptional processes are orchestrated by RNA-binding proteins. However, the factors that coordinate key developmental transitions within the oligodendrocyte lineage to enable OPC homeostasis and myelin dynamics are not well understood.

TDP-43 (TAR DNA-binding protein $43 \mathrm{kDa}$ ) is a DNA/RNA-binding protein that serves as a master regulator of RNA metabolism, controlling transcriptional integrity, post-transcriptional stability and localization of mRNAs (Warraich et al. 2010). Within the nucleus, TDP-43 prevents incorporation of cryptic exons into mature mRNA by binding to UG-rich motifs within intronic sequences (Ling et al. 2015). Loss of TDP-43 in neurons results in missplicing of pre-mRNAs, resulting in gain and loss of function alterations in the landscape of expressed proteins that influence their structure, function and longevity (Ling et al. 2015; Donde et al. 2019; Ma et al. 2021; Brown et al. 2021). In many neurodegenerative diseases, including frontotemporal dementia (FTD), Alzheimer's disease (AD), amyotropic lateral sclerosis (ALS), and multiple sclerosis (MS), cytoplasmic mislocalization and aberrant aggregation of TDP-43 have been observed in affected regions of the CNS (Neumann et al. 2006; Ling et al. 2015; Sun et al. 2017; Masaki et al. 2020; Salapa et al. 2020). Moreover, mutations in TARDBP are responsible for both familial and sporadic forms of ALS (Kapeli, Martinez, and Yeo 2017; Ince et al. 2011), suggesting that altered mRNA processing by TDP-43 may contribute to cellular 
pathology and functional impairment in both sporadic and inherited forms of neurodegenerative disease.

Although neurons have been the primary focus of research into TDP-43 associated pathologies, nuclear exclusion and cytoplasmic aggregation of TDP-43 also occur in glial cells in neurodegenerative diseases, such as MS (Neumann et al. 2006; Masaki et al. 2020; Rohan et al. 2014), suggesting that glial cell dysfunction could impair both OPC homeostasis and remyelination. However, much less is known about the role of TDP-43 in mRNA metabolism or the impact of its loss within oligodendroglia at distinct stages of maturation.

Genetic deletion of TDP-43 in mice results in embryonic lethality due to impaired expansion of inner cell mass during early embryogenesis (Sephton et al. 2010), suggesting that it is essential for cell survival. However, selective deletion experiments indicate that the effects of TDP-43 are cell type-specific and diverse (Jeong et al. 2017), reflecting differences in transcriptional state. In neurons, conditional inactivation of TDP-43 induces impairment in neuronal function and progressive neurodegeneration (Donde et al. 2019; Iguchi et al. 2013; Yang et al. 2014; Wu et al. 2019). Conditional knockout of Tardbp in microglia enhanced expression of NF-kB and NLRP3, leading to a more activated phenotype characterized by enhanced phagocytosis (Zhao et al. 2015; Paolicelli et al. 2017), while loss of TDP-43 in astrocytes promoted their transition to a reactive A1 phenotype associated with neuronal injury (Peng et al. 2020; Walker et al. 2014). In Schwann cells, genetic deletion of Tardbp did not affect their survival or myelinic potential, but impaired formation and maintenance of paranodal junctions (Chang et al. 2021), while deletion from both newly generated oligodendrocytes and Schwann cells induced necroptosis of oligodendrocytes and early mortality (J. Wang et al. 2018). These results indicate that TDP-43 regulates transcriptional integrity of different genes based on cellular context, highlighting the need to define TDP-43 functions within different cellular states. As oligodendroglia consist of both proliferating progenitors and cells in distinct states of maturation, their unique transcriptional profiles may render them differentially sensitive to loss of TDP-43.

Here, we used in vivo targeted genetic manipulations of the oligodendrocyte lineage to define the consequences of TDP-43 loss of function in the mouse brain. OPCs were the most vulnerable to this manipulation, as selective deletion of TDP-43 from OPCs resulted in their rapid death, progressing from the corpus callosum to the overlying cortical gray matter. However, this progenitor depletion was transient, as homeostatic proliferation of OPCs that retained TDP-43 expression led to rapid repopulation and restoration of 
their normal density. Unexpectedly, the consequences of deletion of TDP-43 in oligodendrocytes were dependent on their stage of maturation. Early deletion resulted in the progressive degeneration of mature oligodendrocytes, leading to seizures and premature lethality. In contrast, late-deletion largely spared oligodendrocytes, and mice survived without seizures, indicating that TDP-43 may be dispensable within mature oligodendrocytes. Strikingly, both early and late manipulation of TDP-43 in oligodendrocytes led to profound morphological changes, accompanied by thinner and fewer myelin sheaths, as well as progressive, inappropriate wrapping of neuronal somata and blood vessels. Conditional removal of TDP-43 from oligodendrocytes in the adult CNS induced similar morphological changes and was associated with profound hindlimb weakness. Differential transcriptional analysis of oligodendrocytes revealed that loss of TDP-43 led to missplicing of RNAs encoding key genes involved in oligodendrocyte morphogenesis and myelination, changes that may contribute to abnormal neuronal activity and neurodegeneration in diverse neurological diseases.

\section{Results}

\section{Selective deletion of TDP-43 from OPCs induces their progressive loss}

Oligodendrocytes are derived from an abundant, widely distributed population of lineage restricted progenitors, termed oligodendrocyte precursor cells (OPCs), that maintain their density through local homeostatic proliferation (Hughes et al. 2013). The dynamic nature of these cells may render them particularly susceptible to environmental and genetic perturbations. To determine how loss of TDP-43 affects OPCs in vivo, we selectively deleted Tardbp from OPCs in young adult Pdgfra-CreER;Tardbp ${ }^{f / / f l} ; R C E$ (PDGFRa-TDP43 cKO) mice, by administering tamoxifen at P90 and then collecting brain tissue two weeks later (P90+14) (Figure 1A). Immunolabeling for EGFP and NG2, a proteoglycan highly expressed by OPCs, revealed that this manipulation induced recombination in most OPCs (EGFP+NG2+/NG2+ cells: $94.75 \pm 0.75 \%, n=4)$ (Figure 1B), resulting in near-complete depletion of OPCs from the corpus callosum, while those in the overlying cortical gray matter were preserved (Figure 1C,E; Figure 1D, panel I) (OPCs/mm³: Corpus callosum $14 \mathrm{dpi}$, Control = 6,910 \pm 201 ; cKO $=987 \pm 201, n=3, p<0.001$, one-way ANOVA with Tukey's multiple comparisons test). However, when the interval between tamoxifen administration and sacrifice was increased to 30 days (P90+30), OPCs in gray 
matter were also depleted (Figure 1C,E; Figure 1D, panel ii) (OPCs $/ \mathrm{mm}^{3}$ : Cortex 30 dpi Control = 5,247 \pm 236 ; $\mathrm{cKO}=811 \pm 187, \mathrm{n}=3, \mathrm{p}<0.001$, one-way ANOVA with Tukey's multiple comparisons test). Remarkably, OPCs in white matter had repopulated by this time, and highly polarized OPCs were visible migrating out of the corpus callosum into the gray matter (Figure 1C, red arrowhead; Figure 1D, panel iii; Figure 1E). When the interval between tamoxifen administration and sacrifice was increased by another 30 days (P90+60), OPCs had regained their normal density and tiled distribution throughout gray and white matter (Figure 1C,E). As expected, this repopulation was associated with enhanced proliferation of OPCs, visible by increased Ki-67 immunoreactivity in PDGFRa-TDP43 cKO (Figure 1F; Figure 1-figure supplement 1A). Despite this extensive death of OPCs, there were no signs of astrogliosis, as assessed by GFAP immunoreactivity (Figure 1-figure supplement 1B), in accordance with the tolerance to normal turnover of these cells (Hughes et al. 2013). Deletion of Tardbp in P180 mice also resulted in a robust loss of OPCs in the corpus callosum within 14 days (P180+14) (Figure 1-figure supplement 1C), indicating that the dependence on TDP-43 extends into the adult CNS. Together, these results show that TDP-43 is required for the survival and homeostasis of oligodendrocyte progenitors.

\section{Deletion of TDP-43 from premyelinating oligodendrocytes impairs oligodendrocyte survival}

OPCs undergo a profound series of structural and physiological changes as they differentiate into myelinating oligodendrocytes, a transition enabled by activation of distinct gene regulatory networks expressed at different stages of their maturation (Xu et al. 2020; He et al. 2017). To determine if postmitotic oligodendrocytes are similarly dependent on TDP-43, we deleted Tardbp from these cells using two constitutive Cre lines which differ in their timing of expression during oligodendrocyte maturation: Mobp-iCre, a novel BAC transgenic line that we developed (see Methods) (Figure 2-figure supplement 1), and Mog-iCre, which has been used extensively to manipulate mature oligodendrocytes (Buch et al. 2005; Larson et al. 2018) (Figure 2A). Single cell RNA-Seq results indicate that Mobp expression is robust at the premyelinating oligodendrocyte stage, whereas expression of Mog does not increase substantially until the myelin-forming stage (Marques et al. 2016; Hrvatin et al. 2018; Figure 2-figure supplement 2). Gene expression analysis of oligodendroglia at these stages revealed that many mRNAs are differentially expressed, including Gadd45a, which participates in 

available under aCC-BY-NC-ND 4.0 International license.

DNA methylation, and Opalin (Tmem10) that has been shown to promote oligodendrocyte differentiation

(Barreto et al. 2007; de Faria et al. 2019; Figure 2-figure supplement 3), suggesting that the consequences of TDP-43 may be distinct.

Abolishing TDP-43 expression at these different stages resulted in very different outcomes. Mice in which TDP-43 was constitutively removed from premyelinating oligodendrocytes (Mobp-iCre;Tardbp $\left.p^{f / / f l ;} ; R C E\right)$ (Mobp-TDP43 KO) began to exhibit spontaneous seizures at P110 (Figure 2B, red arrowhead;

Supplementary Video 1) and 100\% died prematurely by P180 (Figure 2B, dark orange line), similar to the phenotype exhibited by Cnp-Cre;Tardbp ${ }^{f / f l}$ mice (J. Wang et al. 2018), in which recombination occurs in OPCs, early postmitotic oligodendrocytes, and Schwann cells in the PNS (Lappe-Siefke et al. 2003). In contrast, mice in which TDP-43 was deleted from mature oligodendrocytes (Mog-iCre;Tardbp ${ }^{f / f t} ;$ :RCE) (Mog-TDP43 KO) did not exhibit spontaneous seizures or other gross behavioral abnormalities and survived as well as controls (Figure 2B, blue lines).

In contrast to the extensive demyelination and oligodendrocyte necroptosis observed in CnpCre;Tardbp $p^{f / f t}$ mice (J. Wang et al. 2018), there was no change in the density of ASPA+ mature oligodendrocytes in the motor cortex of Mobp-TDP43 KO or Mog-TDP43 KO mice at P30, P90, or P180 (end stage) (Figure 2C,D). However, degenerating oligodendrocytes can be rapidly replaced through differentiation of OPCs (Kang et al. 2013), obscuring extensive cell loss. As remaining OPCs proliferate to maintain their density, higher rates of OPC proliferation are associated with oligodendrocyte degeneration (Kang et al. 2013). In accordance with the different behavioral phenotypes of the Mobp-TDP43 KO and Mog-TDP43 KO mice, OPCs also exhibited strikingly different behaviors in these animals. Early deletion of TDP-43 in premyelinating oligodendrocytes (Mobp-TDP43 KO) was associated with a dramatic increase in Ki-67+ OPCs at P90 (Figure 2E,F) (Ki-67+ OPCs/mm³: Mobp-TDP43 Control = $71 \pm 45 ;$ Mobp-TDP43 KO = $941 \pm 121, \mathrm{n}=4$, $\mathrm{p}<0.001$, oneway ANOVA with Tukey's multiple comparisons test), whereas deletion of TDP-43 from mature oligodendrocytes (Mog-TDP43 KO) was not associated with a significant change in OPC proliferation (Figure 2E,F) (Ki-67+ OPCs: Mog-TDP43 Control = $24 \pm 24$; Mog-TDP43 KO = $212 \pm 89, \mathrm{n}=4, \mathrm{p}>0.05$, one-way ANOVA with Tukey's multiple comparisons test). Moreover, there was an increase in the number of newlyformed oligodendrocytes in Mobp-TDP43 KO, as assessed by the emergence of cells that expressed IncOL1 
(Figure 2-figure supplement 4A), a long non-coding RNA that is transiently expressed in premyelinating

oligodendrocytes (He et al. 2017), suggesting that there is an increased turnover of oligodendrocytes.

Astrogliosis (visible through the increase in GFAP immunoreactivity) was also prominent in Mobp-TDP43 KO mice (Figure 2-figure supplement 4B,C), further supporting the conclusion that early deletion of TDP-43 leads to degeneration and subsequent regeneration of oligodendrocytes. Together, these results indicate that there is a critical period for TDP-43 function during oligodendrocyte maturation, with deletion at an early stage leading to progressive oligodendrocyte degeneration, seizures and premature death, consequences that are avoided when oligodendrocytes mature beyond this stage.

\section{TDP-43 loss in oligodendrocytes results in thinner myelin, fewer myelinated axons, and aberrant nodes}

\section{of Ranvier}

Despite the eventual vulnerability of oligodendrocytes to loss of TDP-43, in both Mobp-TDP43 KO and MogTDP43 KO mice, oligodendrocytes were able to mature and form myelin sheaths, global myelin tracts within the brain were established (Figure 3A), and there was no evidence of astrogliosis early in development (P30) (Figure 3-figure supplement 1). To determine if oligodendrocytes in these mice were capable of forming normal myelin at the ultrastructural level, we performed transmission electron microscopy (TEM) of the corpus callosum (Figure 3A, red boxes). Myelinated axons in Mobp-TDP43 KO and Mog-TDP43 KO mice had significantly higher g-ratios than controls at both P90 and P180 (Figure 3B,C), with thinner sheaths formed (Figure 3D). Although axons with diameters less than $0.6 \mu \mathrm{m}$ were not as severely affected at P90, their myelin was also markedly thinner in P140-180 mice. In addition to thinner myelin sheaths, the number of myelinated axons was also reduced in both oligodendrocyte TDP-43 knockouts (Figure 3E,F). These results indicate that despite achieving a mature myelinating stage, the total myelin output of TDP-43 deficient oligodendrocytes is ultimately lower (Summarized in Figure 3-figure supplement 2).

In peripheral nerves, loss of TDP-43 from Schwann cells results in complete loss of paranodal junctions and a 50\% decrease in conduction velocity (Chang et al. 2021). Immunocytochemical analysis revealed that TDP-43-null oligodendrocytes also frequently exhibited abnormal nodes of Ranvier (NOR). While normal NOR exhibit focal localization of $\beta$ IV-spectrin at the node flanked by Caspr within the paranodes (Figure 3-figure 
supplement 3A, yellow arrowheads), in mice with TDP-43 KO oligodendrocytes, nodes often consisted of Caspr triads and $\beta$ IV-spectrin doublets (Figure 3-figure supplement 3A, red arrowheads). EM analysis revealed that some axons exhibited double myelination (Figure 3G), which may contribute to these macroscopic changes in organization of node-associated proteins (Figure 3-figure supplement 3B), as well as unusual accumulation of mitochondria and vacuoles in the inner tongue.

\section{Oligodendrocytes without TDP-43 undergo profound morphological changes}

To define the progressive structural changes exhibited by TDP-43 deficient oligodendrocytes, we examined their morphologies in Mobp-TDP43 KO and Mog-TDP43 KO mice using EGFP (expressed from the conditional RCE transgene) (Sousa et al. 2009). Histological analysis of motor cortex in these mice revealed that oligodendrocyte density gradually increased from P30 to P180 in both control and mutant (KO) mice (Figure 2D); however, while EGFP was largely restricted to oligodendrocyte somata in controls, due to the limited cytoplasm in myelin sheaths, mice with TDP-43 deficient oligodendrocytes exhibited a dramatic increase in EGFP fluorescence in the surrounding parenchyma at P90 and P180 (Figure 4A). This morphological change in oligodendrocytes was observed throughout the brain, as well as the optic nerve and spinal cord (Figure 4figure supplement 1), suggesting that this phenotype is fully penetrant in the CNS. Repetitive in vivo two photon imaging of individual oligodendrocytes in the motor cortex of Mobp-TDP43-RCE KO mice over two weeks revealed that these aberrant structures are highly dynamic (Figure 4-figure supplement 2;

Supplementary Video 2), indicating that these normally highly stable cells exhibit enhanced growth when TDP43 is absent. High resolution imaging revealed that much of this additional EGFP fluorescence arose from thick cytoplasmic processes of oligodendrocytes that often ended in circular or cuff-like structures (Figure 4B,C). Immunostaining for NeuN revealed that circular structures arose from inappropriate wrapping of neuronal cell bodies (Figure 4D,E; Supplementary Video 3). These abnormal associations were not rare events and were visible in single coronal brain sections immunostained for NeuN and EGFP (Figure 4-figure supplement 3, yellow arrowheads).

As the cuff-like structures are reminiscent of astrocyte endfeet (Gundersen et al. 2014), we labeled blood vessels with GS-Isolectin, revealing that EGFP+ oligodendrocyte processes also co-localized with these 
bioRxiv preprint doi: https://doi.org/10.1101/2021.11.09.467933; this version posted November 9, 2021. The copyright holder for this preprint

(which was not certified by peer review) is the author/funder, who has granted bioRxiv a license to display the preprint in perpetuity. It is made available under aCC-BY-NC-ND 4.0 International license.

tubular structures (Figure 4F). To determine if these structures were capillaries, we used in vivo two photon imaging in living Mobp-TDP43-RCE KO mice to visualize both oligodendrocyte processes and capillaries after a retro-orbital injection of dextran-rhodamine. With 4D imaging, it was possible to follow the cytoplasmic processes from individual oligodendrocytes, revealing that they extended unbranched processes to ensheath rhodamine-labeled capillaries (Figure 4G). Histological analysis revealed that regions of capillaries surrounded by oligodendrocyte cuffs exhibited reduced aquaporin 4 immunoreactivity (Figure 4-figure supplement $4 \mathrm{~A}$ ), a protein restricted to astrocyte endfeet (Gundersen et al. 2014), suggesting that these oligodendrocyte wraps may displace or alter the physiology of astrocytes at capillaries. Remarkably, we also found that some TDP-43 KO oligodendrocytes exhibited immunoreactivity to Ki-67 (Figure 4-figure supplement 4B), suggesting that these cells are reverting to a less mature phenotype. Together, these results indicate that TDP-43 is required maintain the structure of oligodendrocytes and myelin throughout the CNS.

\section{Conditional deletion of TDP-43 from oligodendrocytes in the adult CNS induces abnormal} morphological changes, motor discoordination and premature lethality

The results above indicate that constitutive deletion of TDP-43 from myelinating oligodendrocytes induces a profound morphological transformation, and when removed early in their maturation, results in oligodendrocyte degeneration, seizures and death. Although oligodendrocytes continue to be generated in the adult CNS, most oligodendrocytes are produced in the first two postnatal months (Bergles and Richardson 2016), indicating that these changes primarily manifest in developing tissue. To determine if loss of TDP-43 function in oligodendrocytes in the mature brain evokes comparable changes, we generated Mobp-iCreER mice, which allow selective Cre-dependent recombination in oligodendrocytes in the adult CNS (See Methods; Figure 2figure supplement 1). When tamoxifen was administered to P90 Mobp-iCreER;Tardbp ${ }^{f / / f l} ; R C E$ mice and analyzed 30 days later (P90+30), ASPA+ oligodendrocytes were present in the motor cortex with morphologies comparable to controls (Mobp-iCreER;Tardbp ${ }^{++,}$fl/+ $)$(Figure 5A,B). However, when TDP-43 mutant mice were analyzed 90 days later (P90+90), the majority of oligodendrocytes exhibited hypertrophy, as well as cytoplasmic ensheathment of neuronal cell bodies and capillaries (Figure 5B, yellow arrowhead), indicating that TDP-43 is also required to maintain oligodendrocyte structure in the adult CNS. However, the behavioral 
consequences of TDP-43 deletion in the mature CNS were distinct, as these mice exhibited progressive motor problems, including limp tails, hindlimb clasping (Figure 5C) and hindlimb weakness (Figure 5D), but not seizures or premature lethality. Although this transformation of oligodendrocytes did not lead to degeneration of motor neurons (Figure 5-figure supplement 1), the spinal cord exhibited enhanced GFAP immunoreactivity (Figure 5E,F), indicative of widespread inflammation, which has been shown to impair motor function without loss of spinal motor neurons (J. Wang et al. 2018). Thus, adult-onset loss of TDP-43 function in oligodendrocytes, which may occur in disease and injury states (Wiesner et al. 2018; Sun et al. 2017), triggers phenotypes commonly observed in mouse models of amyotrophic lateral sclerosis (ALS) and Parkinson's disease (PD) (Wong and Martin 2010; Lieu et al. 2013).

\section{TDP-43 regulates splicing and represses cryptic exon incorporation in oligodendrocytes}

TDP-43 is a highly conserved, multifunctional protein that regulates key aspects of RNA processing. Previous studies have shown that loss of nuclear TDP-43 function, through genetic deletion or disease-induced mislocalization, is sufficient to cause aberrant incorporation of intronic sequences (cryptic exons) into mature mRNA that can alter protein expression and function (Ling et al. 2015; Sun et al. 2017; Donde et al. 2019). Due to the unique complement of RNAs present in different cell types and differences in intron-exon boundaries between organisms, these changes are both cell type and species specific (Jeong et al. 2017). To define the molecular consequences of TDP-43 loss of function in oligodendrocytes, we used fluorescence activated cell sorting (FACS) to selectively isolate oligodendrocytes from the cortex of P30 Mobp-TDP43-RCE KO and MogTDP43-RCE KO mice (and controls) prior to the onset of phenotypic changes (Figure 4A; Figure 3-figure supplement 1), and performed bulk mRNA sequencing (RNA-Seq) to determine gene expression changes (Figure 6A). In both mouse lines, hundreds of genes were differentially expressed, comprising 3-6\% of the mouse genome (Figure 6B; Figure 6-figure supplement 1), consistent with the magnitude of changes observed in other cell types and the high incidence of UG-repeats recognized by TDP-43 in the genome (Humphrey et al. 2017). The differential gene expression profiles and gene ontology (GO) analysis were also distinct between the mutant mouse lines (Figure 6B; Figure 6-figure supplement 2), with early deletion 
resulting in changes in mRNA processing and cell localization, and latter deletion resulting in changes in regulation of gene expression and metabolic processes.

Analysis of the top $1 \%$ of the highest expressed genes enriched in oligodendrocytes, many of which are involved in oligodendrocyte development and myelination, revealed that cryptic exons were often incorporated in their mRNAs (Figure 6F). These included Ermn (Ermin), an oligodendrocyte-specific cytoskeletal protein that regulates process branching and sheath extension(Brockschnieder et al. 2006). TDP-43 loss resulted in the emergence of a novel cryptic exon in intron 2 of the Ermn transcript (Figure 6C). RT-PCR validation using whole mouse brain indicated that this aberrant splicing generated novel splice isoforms, arising from cryptic exon incorporation, exon extension and truncation (Figure 6D) that may lead to both gain and loss of function. Total Ermin protein was significantly lower in Mobp-TDP43-RCE KO brains compared to controls (Figure 6E), and immunohistochemical staining revealed that Ermin was no longer detected in oligodendrocyte somata in these animals (Figure 6-figure supplement 3). Thus, TDP-43 deficiency leads to an early missplicing of Ermn mRNA, resulting in a partial loss of functional protein. These results indicate that progressive loss of TDP-43 from oligodendrocytes in the adult CNS leads to altered splicing of key regulators of oligodendrocyte growth and morphogenesis, disrupting myelin patterns, inducing gliosis and impairing neuronal function.

\section{Discussion}

New oligodendrocytes are generated in the adult CNS to modify circuits and restore myelin lost through injury or disease (Gibson et al. 2014; Orthmann-Murphy et al. 2020). This oligodendrogenesis requires transformation of highly dynamic, proliferative progenitors into stable, postmitotic oligodendrocytes that exhibit extraordinary longevity (Tripathi et al. 2017). The profound structural and functional changes experienced by oligodendrocyte lineage cells are orchestrated by a family of RNA binding proteins that ensure transcripts are spliced correctly and delivered to their appropriate location within the cell prior to translation (Müller et al. 2013). Cellular stress or direct mutation of these genes can lead to mislocalization and progressive loss of their function, contributing to cellular pathology in diverse neurodegenerative diseases (Kapeli, Martinez, and Yeo 2017; Purice and Taylor 2018), but the consequences of these effects within oligodendroglia are not well understood. As oligodendrocyte lineage cells continue to exist in a dynamic developmental continuum in the 
adult CNS, these changes may influence progenitor homeostasis, lineage progression, cellular survival and function, depending on the stage at which gene function is disrupted.

To genetically interrogate the role of TDP-43 within different stages of oligodendrocyte maturation, we employed four different Cre and CreER mouse lines: 1) Pdgfra-CreER ${ }^{T 2}$, 2) Mobp-iCre, 3) Mog-iCre, and 4) Mobp-iCreER ${ }^{T 2}$, allowing Tardbp inactivation at discrete stages within the oligodendrocyte lineage in both the developing and mature CNS. Bulk RNA-Seq of purified oligodendrocytes from Mobp-iCre and Mog-iCre mouse lines showed that this approach was able to target different stages of oligodendrocyte development. In particular, oligodendrocytes labeled by Mobp-iCre showed higher expression of genes enriched in newlyformed oligodendrocytes, such as Gpr37 and Mag, whereas those labeled by Mog-iCre had higher expression of genes enriched in myelin-forming and mature oligodendrocytes, such as Gamt and Opalin (Figure 6—figure supplement 4). Therefore, these two mouse lines, in combination with Pdgfra-CreER mice to manipulate OPCs (Kang et al. 2010), allowed specific interrogation of TDP-43 function at distinct developmental stages, revealing a differential requirement for TDP-43 in cell survival and structural maintenance as OPCs transform into myelinating oligodendrocytes.

\section{Homeostasis promotes rapid recovery after OPC depletion}

Inducible genetic deletion of Tardbp within OPCs resulted in their rapid degeneration, with loss first detected in the white matter of the corpus callosum two weeks after tamoxifen exposure, followed closely by OPC depletion in cortical gray matter, demonstrating that these progenitors require TDP-43 for survival. OPCs represent the largest population of actively dividing cells in the brain outside SVZ and SGZ germinal zones (Dawson et al. 2003), and maintain a constant density through homeostatic proliferation, in which neighboring cells are induced to divide to replace cells lost through death or differentiation (Hughes et al. 2013). Proliferative cells in many tissues are particularly vulnerable to perturbations in RNA processing, as they undergo metabolic reprogramming requiring extensive transcriptional reorganization (Petasny et al. 2021). Thus, death of only a few proliferating OPCs upon removal of TDP-43 is likely to induce a cascading depletion, capturing neighboring cells (also TDP-43 deficient) as they are induced to proliferate. The higher basal rate of 
bioRxiv preprint doi: https://doi.org/10.1101/2021.11.09.467933; this version posted November 9, 2021. The copyright holder for this preprint (which was not certified by peer review) is the author/funder, who has granted bioRxiv a license to display the preprint in perpetuity. It is made available under aCC-BY-NC-ND 4.0 International license.

OPC proliferation in white matter, reflecting their higher rate of differentiation (Baracskay et al. 2002; Viganò et al. 2013), may be responsible for more rapid loss of OPCs in this region.

Despite decimation of OPCs after TDP-43 deletion, they were restored to their original density in both gray and white matter within 30 days. Because Tardbp was not inactivated in all OPCs (the proportion limited by the efficiency of tamoxifen-induced recombination), surviving cells that retain TDP-43 are expected to proliferate to reconstitute the population. Consistent with this hypothesis, all OPCs after 30 days of recovery were EGFP negative (Figure 1-figure supplement 1D), indicating that they did not experience Cre activity. These results imply that focal loss of OPCs arising from deficits in TDP-43 should not lead to persistent depletion. Indeed, OPCs have been shown to be exceptionally resistant to perturbations in their distribution and density (Xing et al. 2021; Đặng et al. 2019), and rapidly restore their numbers after mass differentiation following demyelination in mice (Baxi et al. 2017; Penderis, Shields, and Franklin 2003). Nevertheless, reductions in OPC density have been observed in some human MS lesions (Chang et al. 2000), suggesting that other environmental changes, such as persistent inflammation or gliosis, which may induce TDP-43 mislocalization, may impede their homeostasis and impair their ability to detect demyelinated axons and generate new oligodendrocytes.

\section{Stage-dependent oligodendrocyte survival in the absence of TDP-43}

The differentiation of OPCs into mature, myelinating oligodendrocytes is associated with dramatic structural and functional changes, in which highly motile OPCs stabilize, elaborate processes and select targets for myelination (Kirby et al. 2006; Almeida et al. 2011). Previous studies of Tardbp inactivation using Cnp-Cre mice (Wang et al. 2018; Chang et al. 2021), which recombines in the late progenitor and early pre-myelinating stages, indicate that loss of TDP-43 during this transition period leads to RIPK1-mediated necroptosis of oligodendrocytes (J. Wang et al. 2018). We used two constitutive Cre lines (Mobp-iCre and Mog-iCre) expressed at different stages (early and late) of the maturation of postmitotic oligodendrocytes to determine whether the effects of TDP-43 loss depend on their state of differentiation. In contrast to TDP-43 deficient OPCs, oligodendrocytes were generated, and myelin sheaths were formed in both lines despite inactivation of Tardbp. As the half-life of TDP-43 in vitro was measured to be 12-34 hours (S.-C. Ling et al. 2010; E. B. Lee, 
Lee, and Trojanowski 2011), it is possible that sufficient residual TDP-43 RNA/protein remains from the OPC stage to enable these initial transitions. Although oligodendrocytes and myelin were generated, TDP-43 deficient oligodendrocytes formed sheaths with fewer wraps and overall fewer axons were myelinated, similar to that observed after Cnp-Cre mediated deletion (J. Wang et al. 2018). Reconstructions of individual oligodendrocytes at this stage revealed that fewer sheaths were formed per cell on average, indicating that the overall myelin output of these newly formed oligodendrocytes is compromised in the absence of TDP-43. However, the ultimate outcome of these manipulations was distinct, with early deletion (using Mobp-iCre) resulting in oligodendrocyte degeneration, seizures and premature death by six months of age. This phenotype is similar to, but not as severe as that observed in Cnp-Cre;Tardbp ${ }^{\text {t/flt }}$ mice, in which mature oligodendrocytes, OPCs, premyelinating oligodendrocytes, and Schwann cells were genetically manipulated (Lappe-Siefke et al. 2003; J. Wang et al. 2018), indicating that disruption of oligodendrocyte TDP-43 levels is sufficient to enhance neuronal excitability and induce premature death.

Although oligodendrocyte density remained stable after Mobp-iCre-mediated Tardbp inactivation, reactive gliosis occurred throughout the CNS and there was an increase in premyelinating oligodendrocytes (IncOL1+) and enhanced proliferation of OPCs, indicative of oligodendrocyte degeneration, similar to the phenotypic changes observed after inducible deletion of oligodendrocytes in the adult CNS (Traka et al. 2015; Oluich et al. 2012). Previous studies have shown that subtler manipulations of mature oligodendrocytes, such as reduction in expression of the inwardly rectifying potassium channel $\mathrm{K}_{\mathrm{ir}} 4.1$ (Larson et al. 2018) or deletion of the lactate transporter MCT1 (Philips et al. 2021), is sufficient to alter neuronal excitability, highlighting possible functional consequences of TDP-43 loss from these myelinating cells.

Unexpectedly, inactivation of Tardbp from oligodendrocytes at a later developmental stage (with MogiCre) led to a strikingly different outcome: oligodendrocytes survived, OPC proliferation was not enhanced and there was no gliosis. Correspondingly, these animals also did not exhibit seizures or premature death. Bulk RNA-Seq transcriptional analysis of oligodendrocytes with early and late deletion, even prior to the phenotypic changes in Mobp-iCre mice (P30), revealed that pathways involved in gene expression, cellular localization, cell adhesion, and metabolism were affected. Further, differential gene expression analysis of early, premyelinating and myelinating oligodendrocytes from obtained through single-cell RNA sequencing (Hrvatin et 
al. 2018) revealed that different transcription factors, such as Mycl, and transporters, such as MCT1 (SIc16a1), change in gene expression as oligodendrocytes mature (Figure 2-figure supplement 3). Thus, rapid changes in transcriptional activity during cellular maturation can profoundly alter the impact of TDP-43 depletion, with deficits occurring earlier in maturation leading to more severe outcomes.

The phenotypes observed in response to deletion of TDP-43 from newly generated oligodendrocytes, including subsequent seizures and premature death, may also reflect developmental changes in neural circuits, as this manipulation inactivated Tardbp during a critical phase of brain maturation. Indeed, deletion of TDP-43 from oligodendrocytes in the adult CNS (using Mobp-iCreER) led to distinct pathological changes, such as hindlimb weakness, hindlimb clasping and limp tail, phenotypes not observed with developmental Tardbp inactivation, and these mice did not exhibit seizures or premature death. Although these distinct phenotypes may arise from differences in the proportion of oligodendrocytes affected, they mirror functional differences observed in neurodevelopmental and neurodegenerative diseases. In neurodevelopmental disorders, such as autism spectrum disorders and schizophrenia, abnormal myelination and altered density of oligodendrocytes have been correlated with neural hyperexcitability and circuit dysfunction (Phan et al. 2020; Fields 2008). In contrast, oligodendrocyte turnover and demyelination in the adult CNS have been shown to be accompanied by inflammation and neuronal death in neurodegenerative diseases, such as ALS and AD (Kang et al. 2013; Desai et al. 2010; Behrendt et al. 2013). These results suggest that the consequences of TDP-43 loss within the oligodendrocyte lineage depends not only on their stage of maturation, but also the environment in which it occurs, with progressive loss in the adult CNS sufficient to impair motor coordination, a hallmark of neurodegenerative diseases such as ALS.

\section{Aberrant target ensheathment in the absence of TDP-43}

In vitro studies indicate that oligodendrocytes have an intrinsic ability to wrap structures of appropriate caliber (> $0.4 \mu \mathrm{m}$ ), including inert nanofibers and fixed axons (Rosenberg et al. 2008; Mei, Chong, and Chan 2013 ; S. Lee et al. 2012). However, oligodendrocytes in vivo exhibit exquisite target specificity, forming myelin exclusively around axons of appropriate diameter, while avoiding similarly sized dendrites and other nonneuronal structures, such as glial cell processes and capillaries. Moreover, after an initial period of remodeling, 
the array of myelin sheaths formed by each oligodendrocyte is extremely stable, in terms of position and length along axons. Deletion of TDP-43 from oligodendrocytes either early or late in their maturation resulted in striking, progressive changes in oligodendrocyte morphology, including extension of new processes and wrapping of inappropriate targets, such as neuronal somata and capillaries. Inappropriate myelination of neuronal somata has been observed after deletion of adhesive proteins (e.g. JAM2) from neurons (Redmond et al. 2016), expression of a mutant form of a cell adhesion protein (e.g. Cadm4) in oligodendrocytes (Elazar et al. 2019), or overexpression of myelin basic protein (MBP) (Almeida et al. 2018). Similar aberrant myelination has been reported in MS lesions (Neely et al. 2020), where TDP-43 mislocalization has also be found (Masaki et al. 2020). The morphological changes exhibited by TDP-43 deficient oligodendrocytes suggests that they revert to a pro-growth state (Grinspan et al. 1993; H. Lee et al. 2019), allowing them to overcome repulsive cues or lack of adhesion that normally prevents wrapping of non-axonal structures.

\section{Loss of TDP-43 leads to aberrant RNA splicing}

TDP-43 maintains the integrity of the cellular transcriptome by regulating splicing of pre-mRNAs and suppressing incorporation of cryptic exons. By efficiently binding to UG microsatellite repeats within intronic sequences, TDP-43 ensures that spliceosomes skip over these regions during normal splicing (J. P. Ling et al. 2015). As the specificity of TDP-43 targets primarily depend on the location of these UG tandem repeats, TDP43 dependent cryptic exons are both cell type- and species-specific (Jeong et al. 2017; J. P. Ling et al. 2015). By performing RNA sequencing of TDP-43 deficient oligodendrocytes purified from the brain, we uncovered a novel set of cryptic exons in mRNAs that encode proteins involved in oligodendrogenesis and myelination, changes that resulted from novel cassette insertion, exon extension, and alternative splicing. In case of Ermin, a cytoskeletal protein involved in oligodendrocyte morphogenesis (Brockschnieder et al. 2006), cryptic exon incorporation led to a pronounced decrease in protein expression; however, the phenotypic changes induced by loss of TDP-43 are not the same as that observed in Ermn KO mice (S. Wang et al. 2020; Ziaei et al. 2020). Aberrant splicing of Ermin mRNA is predicted to lead to a truncated N-terminal peptide ( amino acid 1-110) that may produce a dominant negative effect. Moreover, loss of TDP-43 was not selective for Ermin, but led to aberrant splicing of numerous myelin and oligodendrocyte genes (Figure 6F). The combination of gain and loss 
bioRxiv preprint doi: https://doi.org/10.1101/2021.11.09.467933. this version posted November 9 2021. The copyright holder for this preprint

(which was not certified by peer review) is the author/funder, who has granted bioRxiv a license to display the preprint in perpetuity. It is made available under aCC-BY-NC-ND 4.0 International license.

453 of function of the resultant proteins likely contribute to complex phenotype exhibited by these mutant

454 oligodendrocytes.

Oligodendrocyte and myelin abnormalities have been reported in many neurodegenerative diseases

456 known to present with TDP-43 proteinopathy (Kang et al. 2013; Masaki et al. 2020; Zhang et al. 2019).

457 Although cytoplasmic aggregates of TDP-43 are not always present, nuclear clearance of TDP-43 and

458 resulting loss of function is sufficient to cause dramatic alterations in pre-mRNA splicing (Sun et al. 2017).

459 Further investigation of RNA splicing changes in oligodendrocytes in different neurodegenerative diseases may

460 reveal unique pathological signatures associated with disease states that may help predict progression and

461 identify novel therapeutic approaches for reducing the impact of impaired TDP-43 activity. 


\section{Materials and methods}

\section{Generation of Mobp-iCre and Mobp-iCreER mouse lines}

iCreER $^{\mathrm{T} 2}$ sequence was inserted into pBACe3.6_RP23-127H7 to generate Mobp-iCreER ${ }^{\mathrm{T} 2} \mathrm{BAC}$ for injection in C57BL/6 background. Out of five PCR positive founders, one of the founders yielded F1 and F2 generations where Cre recombination was independent of tamoxifen injection. Therefore, this line was then designated as a constitutive Mobp-iCre mouse line (line \#10). Of the other founder lines, the line with highest tamoxifendependent recombination efficiency were selected and maintained as a conditional Mobp-iCreER ${ }^{\top 2}$ mouse line (line \#8, 16) (Figure 2-figure supplement 1).

\section{Animal care and use}

Both female and male mice were used for experiments and randomly assigned to experimental groups. Mice were maintained on a 12-h light/dark cycle, housed in groups no larger than 5 , and food and water were provided ad libitum. All animal experiments were performed in strict accordance with protocols approved by the Animal Care and Use Committee at Johns Hopkins University. All experiments were initially performed with a sample size of 3 (biological replicates) for quantification and statistical analyses, and power analysis was then performed to determine the minimum sample size to achieve sufficient statistical power to detect the effect of TDP-43 loss in different transgenic mouse lines at different timepoints. The following transgenic mouse lines were used in this study:

Pdgfra-CreER (Kang et al. 2010)

Tardbp $p^{\text {floxed }}$ (Chiang et al. 2010)

RCE (Rosa-CAG-LSL-EGFP) (JAX MMRRC stock \#32038) (Sousa et al. 2009)

Mobp-iCre

Mobp-iCreER

Mog-iCre (Buch et al. 2005)

\section{CreER induction}


To induce Tardbp genetic deletion and EGFP expression in the Pdgfra-CreER;Tardbp ${ }^{\text {floxed } ; R C E ~ a n d ~ M o b p-~}$ iCreER;Tardbp $p^{\text {floxed } ; R C E ~ m i c e, ~ P 90 ~ o r ~ P 180-240 ~ m i c e ~ w e r e ~ i n j e c t e d ~ w i t h ~ t a m o x i f e n ~(S i g m a) ~ d i s s o l v e d ~ i n ~}$ sunflower seed oil (Sigma) and administered by intraperitoneal injection daily for five consecutive days at a dose of $100 \mathrm{mg} / \mathrm{kg}$ body weight. Mice were perfused 14, 30, 60, and 90 days from the last day of tamoxifen injection.

\section{Cranial windows and in vivo two-photon microscopy}

Cranial windows were prepared as previously described (Orthmann-Murphy et al. 2020). Briefly, 4 to 8 weekold mice were anesthetized with isoflurane (induction, $5 \%$; maintenance, $1.5-2 \%$, mixed with $0.4-1 \mathrm{~L} / \mathrm{min} \mathrm{O} 2$ ), and their body temperature was maintained at $37^{\circ} \mathrm{C}$ with a thermostat-controlled heating plate. The skin over the right hemisphere was removed and the skull cleaned. A $3 \times 3 \mathrm{~mm}$ region of skull over motor cortex was removed using a high-speed dental drill. A piece of cover glass (VWR, No. 1) was placed in the craniotomy and sealed with VetBond (3M), then dental cement (C\&B Metabond) and a custom metal plate with a central hole was attached to the skull for head stabilization. In vivo imaging sessions began 3 weeks after cranial window procedure in order for the surgery-induced inflammation to subside. During imaging sessions, mice were anesthetized with isoflurane and immobilized by attaching the head plate to a custom stage. Images were collected using a Zeiss LSM 710 microscope equipped with a GaAsP detector using a mode-locked Ti:sapphire laser (Coherent Ultra) tuned to $920 \mathrm{~nm}$.

\section{Immunohistochemistry}

Mice were deeply anesthetized with sodium pentobarbital $(100 \mathrm{mg} / \mathrm{kg})$ and perfused transcardially first with 15$20 \mathrm{~mL}$ room temperature PBS (pH 7.4) followed by $10 \mathrm{~mL}$ ice-cold $4 \%$ paraformaldehyde (PFA in $0.1 \mathrm{M}$ phosphate buffer, pH 7.4). CNS tissues were dissected (e.g. optic nerve, brain, and spinal column) and postfixed in $4 \%$ PFA at $4^{\circ} \mathrm{C}$ for $4-6$ hours or $12-20$ hours depending on the antibodies to be used for immunohistochemistry. The tissues samples were transferred to $30 \%$ sucrose solution (in PBS, $\mathrm{pH} 7.4$ ) for cryoprotection for at least two overnights before sectioning. Tissue samples were frozen in TissueTek and sectioned at $35 \mu \mathrm{m}$ thickness on a cryostat (Thermo Scientific Microm HM 550) at $-20^{\circ} \mathrm{C}$. Tissue sections were 
bioRxiv preprint doi: https://doi.org/10.1101/2021.11.09.467933; this version posted November 9, 2021. The copyright holder for this preprint (which was not certified by peer review) is the author/funder, who has granted bioRxiv a license to display the preprint in perpetuity. It is made available under aCC-BY-NC-ND 4.0 International license.

collected into a 24-well plate with PBS with $0.1 \% \mathrm{NaN}_{3}$ and kept in $4^{\circ} \mathrm{C}$ until use. Free-floating sections were preincubated in blocking solution (10\% normal donkey serum, $0.3 \%$ Triton $\mathrm{X}-100$ in PBS, pH 7.4) for 1 or 2 hours at room temperature, then incubated for 24 to 48 hours at $4{ }^{\circ} \mathrm{C}$ or room temperature in primary antibody. Secondary antibody incubation was performed at room temperature for 2 to 4 hours. Sections were mounted on slides with Aqua Polymount (Polysciences). Images were acquired using a confocal laser-scanning microscope (Zeiss LSM 510 Meta; Zeiss LSM 800; Zeiss LSM 880). The following primary antibodies were used in this study: Rabbit anti-ASPA (Genetex; RRID_AB_2036283), chicken anti-GFP (Aves lab; RRID:AB_2307313), goat anti-GFP (Sicgen; RRID:AB_2333099), mouse anti-MBP (Sternberger; RRID:AB_2564741), chicken anti-MBP (Aves lab; RRID:AB_2313550), rabbit anti-GFAP (Agilent; RRID:AB_10013482), Alexa Fluor 647 isolectin GS-IB4 (Thermo Fisher), rabbit anti-Aquaporin 4 (Sigma; RRID:AB_1844967), mouse anti-NeuN (Millipore; RRID:AB_2298772), mouse anti-CC1 (Millipore; RRID:AB_2242783), mouse anti-Ermin (Gift from E. Peles), guinea pig anti-Caspr (Gift from M. Bhat), rabbit anti-BIV-spectrin (Gift from M. Rasband), goat anti-ChAT (Millipore; RRID:AB_90650), guinea pig anti-NG2 (Generated in D.E. Bergles lab), and rabbit anti-Ki-67 (Abcam; RRID:AB_443209). Appropriate donkey secondary antibodies conjugated to Alexa Fluor 488, Cy3 or Alexa Fluor 546, and Cy5 or Alexa Fluor 647 were used at 1:1,000-2,000.

\section{Transmission electron microscopy (TEM) and g-ratio quantification}

Samples were perfuse-fixed with room temperature PBS and "Karlsson-Schultz" buffer (2.5\% Glutaraldehyde, $4 \%$ Formaldehyde and $0.5 \% \mathrm{NaCl}$ in Phosphate Buffer $\mathrm{pH} 7.3$ ) and post-fixed at $4^{\circ} \mathrm{C}$ for two overnights.

Subsequent TEM processing was performed according to a previously described protocol (Weil et al. 2019). For g-ratio analysis 10 random micrographs covering an area of $\sim 180 \mu \mathrm{m}^{2}$ each were taken at a magnification of 6000x using a LEO912 transmission electron microscope (Carl Zeiss Microscopy, Oberkochen, Germany) with an on-axis 2k CCD camera (TRS, Moorenweis, Germany). For random selection of axons the images were overlaid with a grid and axons on grid crossings were analyzed with a minimum of 100 axons per animal. For g-ratio determination the area of the axon and the corresponding fiber including the myelin sheath were 
measured using Fiji/lmageJ (Schindelin et al. 2012) and the diameters derived assuming circular areas. The gratios were calculated as a ratio between axonal diameter and total fiber diameter.

\section{Image processing and analysis}

Image stacks and time series were analyzed using FIJI/ImageJ. For figure presentation, image brightness and contrast levels were adjusted for clarity. Density and g-ratio quantifications were performed by a blinded observer. Longitudinal image stacks were registered using FIJI plugin "Correct 3D Drift” (Parslow, Cardona, and Bryson-Richardson 2014; Orthmann-Murphy et al. 2020).

\section{Statistical analysis}

Statistical analyses were performed with GraphPad Prism 7 or Excel (Microsoft). All technical replicates (e.g. different brain sections for $\mathrm{IHC}$ ) for each sample were averaged as a single data point. Significance was determined using one-way ANOVA test with Tukey's correction for multiple comparisons or unpaired, twotailed Student's t-test. Each figure legend otherwise contains the statistical tests used to measure significance and the corresponding significance level ( $p$-value). $n$ represents the number of animals (biological replicates) used in each experiment. Data are reported as mean \pm SEM and $p$-value $<0.05$ was considered statistically significant.

\section{Fluorescence-activated cell sorting (FACS)}

Male and female Mobp-TDP43 and Mog-TDP43 mice aged at P30 were cardiac perfused with ice-cold 1x HBSS w/o $\mathrm{Ca}^{2+}$ and $\mathrm{Mg}^{2+}$. Only the cortex was dissected out for downstream processing and mechanically dissociated with a razor blade on ice. The Miltenyi Neural Tissue Dissociation kit was used to perform enzymatic dissociation of the tissue into a single cell suspension, and Myelin Debris Removal solution (Miltenyi) to remove myelin debris. The cells were resuspended in FACS sorting buffer ( $5 \mathrm{~mL}$ of $1 \mathrm{M} \mathrm{HEPES} \mathrm{+}$ $2 \mathrm{~mL}$ of FBS $+800 \mu \mathrm{l}$ of $0.5 \mathrm{M}$ EDTA in $200 \mathrm{~mL} \mathrm{HBSS}$ w/o $\mathrm{Ca}^{2+}, \mathrm{Mg}^{2+}$ ) and filtered through $35 \mu \mathrm{m}$ strainer. The cells were sorted for endogenous GFP fluorescence on BD FACS Aria llu Cell Sorter using a $100 \mu \mathrm{m}$ nozzle at the Ross Flow Cytometry Core Facility at Johns Hopkins University School of Medicine. 


\section{RNA isolation, cDNA library preparation, and sequencing}

RNA was isolated from FACS purified oligodendrocytes using QIAGEN RNeasy Micro Kit following the manufacturer's instructions. cDNA was synthesized by using QIAGEN QuantiTect Reverse Transcription Kit. Due to low amount of cDNA, Nugen Single-cell RNAseq kit was used to generate cDNA libraries for 100 bp paired-end sequencing on Illumina HiSeq (70-100 million paired reads/sample).

\section{Analysis of bulk RNA-Seq data}

Reads were aligned to the latest mouse mm10 reference genome using the STAR spliced read aligner with default parameters. Total counts of read-fragments aligned to known gene regions within the mouse $\mathrm{mm} 10$ RefSeq reference annotation were used as the basis for quantification of gene expression. Fragment counts were derived using HTS-seq program using mm10 Ensembl transcripts as the model. Various QC analyses were conducted to assess the quality of the data and to identify potential outliers (e.g. the level of mismatch rate, mapping rate to the whole genome, repeats, chromosomes, and key transcriptomic regions). Principal component analysis (PCA) correction was performed to correct for batch effects and differences in sample RNA integrity number (RIN). Differentially expressed genes were identified using EdgeR Bioconductor package and ranked based on adjusted $p$-values (FDR) of $<0.05$.

\section{RT-PCR}

RNA was isolated from whole mouse brain tissue using ReliaPrep RNA Tissue Miniprep System (Promega) following the manufacturer's instructions. cDNA was synthesized by using QIAGEN QuantiTect Reverse Transcription Kit. RT-PCR primers against normal Ermn and cryptic exon-specific Ermn transcripts were designed using Benchling and Primer3.

\section{Western blotting}

Whole mouse brain tissue was homogenized in $1.5 \mathrm{ml}$ Eppendorf tube with a handheld homogenizer in Pierce RIPA buffer (Thermo Fisher) with Sodium Orthovanadate (Vanadate). After centrifugation at $4^{\circ} \mathrm{C}$, supernatant 
was collected, and the protein concentration was determined using Pierce BCA Protein Assay Kit (Thermo

Fisher). $50 \mu \mathrm{g}$ of protein was loaded into each lane of Mini-Protean TGX gels (Biorad) and ran at $120 \mathrm{~V}$ for 1.5

hours. Protein was transferred onto Immobilon-FL PVDF Membrane (Millipore) at $100 \mathrm{~V}$ for 1.5 hours. Intercept (TBS) Blocking Buffer (Li-Cor) was used for blocking, and the membrane was incubated in primary antibody solution at $4^{\circ} \mathrm{C}$ overnight with gentle shaking. Mouse-Ermin (Mab160; raised against Ermin residues 1-261) and Rabbit-GAPDH (Cell Signaling) primary antibodies were used. IRDye® 680RD Goat anti-Mouse IgG $(H+$ L) (Li-Cor) and IRDye® 800CW Goat anti-Rabbit IgG (H + L) (Li-Cor) were used as secondary antibodies for imaging on Odyssey Imaging Workstation (Li-Cor).

\section{Data availability}

All published tools and reagents will be shared on an unrestricted basis; requests should be directed to the corresponding author.

\section{References}

Almeida, Rafael G., Simon Pan, Katy L.H. H Cole, Jill M. Williamson, Jason J. Early, Tim Czopka, Anna Klingseisen, Jonah R. Chan, and David A. Lyons. 2018. "Myelination of Neuronal Cell Bodies When Myelin Supply Exceeds Axonal Demand." Current Biology 28 (8): 1296-1305. https://doi.org/10.1016/j.cub.2018.02.068.

Almeida, Rafael G, Tim Czopka, Charles Ffrench-Constant, and David A Lyons. 2011. "Individual Axons Regulate the Myelinating Potential of Single Oligodendrocytes in Vivo." Development 138 (20): 4443-50. https://journals.biologists.com/dev/article-abstract/138/20/4443/44691.

Bacmeister, Clara M, Helena J Barr, Crystal R McClain, Michael A Thornton, Dailey Nettles, Cristin G Welle, and Ethan G Hughes. 2020. "Motor Learning Promotes Remyelination via New and Surviving Oligodendrocytes." Nature Neuroscience 23 (7): 819-31. https://doi.org/10.1038/s41593-020-0637-3.

Baracskay, Karen L, Cynthia S Duchala, Robert H Miller, Wendy B Macklin, and Bruce D Trapp. 2002.

"Oligodendrogenesis Is Differentially Regulated in Gray and White Matter of Jimpy Mice." Journal of Neuroscience Research 70 (5): 645-54. https://doi.org/10.1002/jnr.10418. 
bioRxiv preprint doi: https://doi.org/10.1101/2021.11.09.467933; this version posted November 9, 2021. The copyright holder for this preprint (which was not certified by peer review) is the author/funder, who has granted bioRxiv a license to display the preprint in perpetuity. It is made available under aCC-BY-NC-ND 4.0 International license.

Barreto, Guillermo, Andrea Schäfer, Joachim Marhold, Dirk Stach, Suresh K. Swaminathan, Vikas Handa, Gabi Döderlein, et al. 2007. "Gadd45a Promotes Epigenetic Gene Activation by Repair-Mediated DNA Demethylation." Nature 2006 445:7128 445 (7128): 671-75. https://doi.org/10.1038/nature05515.

Baxi, Emily G, Joseph Debruin, Jing Jin, Hayley J Strasburger, Matthew D Smith, Jennifer L OrthmannMurphy, Jason T Schott, et al. 2017. "Lineage Tracing Reveals Dynamic Changes in Oligodendrocyte Precursor Cells Following Cuprizone-Induced Demyelination." Glia 65 (August 2016): 2087-98. https://doi.org/10.1002/glia.23229.

Behrendt, Gwendolyn, Kristin Baer, Annalisa Buffo, Maurice A Curtis, Richard L Faull, Mark I Rees, Magdalena Götz, and Leda Dimou. 2013. "Dynamic Changes in Myelin Aberrations and Oligodendrocyte Generation in Chronic Amyloidosis in Mice and Men." Glia 61 (2): 273-86. https://doi.org/10.1002/GLIA.22432.

Benamer, Najate, Marie Vidal, Maddalena Balia, MC Angulo - Nature communications, undefined 2020, and María Cecilia Angulo. 2020. "Myelination of Parvalbumin Interneurons Shapes the Function of Cortical Sensory Inhibitory Circuits" 11 (1): 1-14. https://doi.org/10.1038/s41467-020-18984-7.

Bergles, Dwight E., and William D. Richardson. 2016. "Oligodendrocyte Development and Plasticity." Cold Spring Harbor Perspectives in Biology 8 (2): 1-28. https://doi.org/10.1101/cshperspect.a020453.

Brockschnieder, Damian, Helena Sabanay, Dieter Riethmacher, and Elior Peles. 2006. "Ermin, a Myelinating Oligodendrocyte-Specific Protein That Regulates Cell Morphology." Journal of Neuroscience 26 (3): $757-$ 62. https://doi.org/10.1523/JNEUROSCI.4317-05.2006.

Brown, Anna-Leigh, Oscar G. Wilkins, Matthew J. Keuss, Sarah E. Hill, Matteo Zanovello, Weaverly Colleen Lee, Flora C.Y. Lee, et al. 2021. "Common ALS/FTD Risk Variants in UNC13A Exacerbate Its Cryptic Splicing and Loss upon TDP-43 Mislocalization." BioRxiv, April, 2021.04.02.438170. https://doi.org/10.1101/2021.04.02.438170.

Buch, Thorsten, Frank L Heppner, Christine Tertilt, Tobias J A J Heinen, Marcel Kremer, F Thomas Wunderlich, Steffen Jung, and Ari Waisman. 2005. "A Cre-Inducible Diphtheria Toxin Receptor Mediates Cell Lineage Ablation after Toxin Administration." Nature Methods 2 (6): 419-26. https://doi.org/10.1038/NMETH762.

Chang, A, A Nishiyama, J Peterson, J Prineas, and B D Trapp. 2000. "NG2-Positive Oligodendrocyte 
bioRxiv preprint doi: https://doi.org/10.1101/2021.11.09.467933; this version posted November 9, 2021. The copyright holder for this preprint (which was not certified by peer review) is the author/funder, who has granted bioRxiv a license to display the preprint in perpetuity. It is made available under aCC-BY-NC-ND 4.0 International license.

Progenitor Cells in Adult Human Brain and Multiple Sclerosis Lesions." The Journal of Neuroscience: The Official Journal of the Society for Neuroscience 20 (17): 6404-12.

https://doi.org/10.1523/JNEUROSCI.20-17-06404.2000.

Chang, Kae Jiun, Ira Agrawal, Anna Vainshtein, Wan Yun Ho, Wendy Xin, Greg Tucker-Kellogg, Keiichiro Susuki, Elior Peles, Shuo Chien Ling, and Jonah R. Chan. 2021. "TDP-43 Maximizes Nerve Conduction Velocity by Repressing a Cryptic Exon for Paranodal Junction Assembly in Schwann Cells." ELife 10 (March). https://doi.org/10.7554/ELIFE.64456.

Chiang, Po Min, Jonathan Ling, Yun Ha Jeong, Donald L. Price, Susan M. Aja, and Philip C. Wong. 2010.

“Deletion of TDP-43 down-Regulates Tbc1d1, a Gene Linked to Obesity, and Alters Body Fat

Metabolism." Proceedings of the National Academy of Sciences of the United States of America 107 (37): 16320-24. https://doi.org/10.1073/pnas.1002176107.

Đặng, Thành Chung, Yoko Ishii, Van De Nguyen, Seiji Yamamoto, Takeru Hamashima, Noriko Okuno, Quang Linh Nguyen, et al. 2019. "Powerful Homeostatic Control of Oligodendroglial Lineage by PDGFRa in Adult Brain." Cell Reports 27 (4): 1073-89.

https://www.sciencedirect.com/science/article/pii/S2211124719304231.

Dawson, Mary R L, Annabella Polito, Joel M Levine, and Richard Reynolds. 2003. "NG2-Expressing Glial Progenitor Cells: An Abundant and Widespread Population of Cycling Cells in the Adult Rat CNS." Molecular and Cellular Neuroscience 24 (2): 476-88. https://doi.org/10.1016/S1044-7431(03)00210-0.

Desai, Maya K., Michael A. Mastrangelo, Deborah A. Ryan, Kelly L. Sudol, Wade C. Narrow, and William J. Bowers. 2010. “Early Oligodendrocyte/Myelin Pathology in Alzheimer's Disease Mice Constitutes a Novel Therapeutic Target." The American Journal of Pathology 177 (3): 1422-35. https://doi.org/10.2353/AJPATH.2010.100087.

Donde, Aneesh, Mingkuan Sun, Jonathan P. Ling, Kerstin E. Braunstein, Bo Pang, Xinrui Wen, Xueying Cheng, Liam Chen, and Philip C. Wong. 2019. "Splicing Repression Is a Major Function of TDP-43 in Motor Neurons." Acta Neuropathologica 138 (5): 813-26. https://doi.org/10.1007/s00401-019-02042-8. Elazar, Nimrod, Anya Vainshtein, Neev Golan, Bharath Vijayaragavan, Nicole Schaeren-Wiemers, Yael EshedEisenbach, and Elior Peles. 2019. "Axoglial Adhesion by Cadm4 Regulates CNS Myelination.” Neuron 
bioRxiv preprint doi: https://doi.org/10.1101/2021.11.09.467933; this version posted November 9, 2021. The copyright holder for this preprint (which was not certified by peer review) is the author/funder, who has granted bioRxiv a license to display the preprint in perpetuity. It is made available under aCC-BY-NC-ND 4.0 International license.

101 (2): 224-31. https://doi.org/10.1016/j.neuron.2018.11.032.

Faria, Omar de, Ajit S. Dhaunchak, Yasmine Kamen, Alejandro D. Roth, Tanja Kuhlmann, David R. Colman, and Timothy E. Kennedy. 2019. "TMEM10 Promotes Oligodendrocyte Differentiation and Is Expressed by Oligodendrocytes in Human Remyelinating Multiple Sclerosis Plaques." Scientific Reports 2019 9:1 9 (1): 1-12. https://doi.org/10.1038/s41598-019-40342-x.

Fields, R. Douglas. 2008. "White Matter in Learning, Cognition and Psychiatric Disorders.” Trends in Neurosciences 31 (7): 361. https://doi.org/10.1016/J.TINS.2008.04.001.

Gibson, Erin M, David Purger, Christopher W Mount, Andrea K Goldstein, Grant L Lin, Lauren S Wood, Ingrid Inema, et al. 2014. "Neuronal Activity Promotes Oligodendrogenesis and Adaptive Myelination in the Mammalian Brain." Science 344 (6183). https://doi.org/10.1126/science.1252304.

Grinspan, J. B., J. L. Stern, B. Franceschini, and D. Pleasure. 1993. “Trophic Effects of Basic Fibroblast Growth Factor (BFGF) on Differentiated Oligodendroglia: A Mechanism for Regeneration of the Oligodendroglial Lineage." Journal of Neuroscience Research 36 (6): 672-80. https://doi.org/10.1002/JNR.490360608.

Gundersen, Georg Andreas, Gry Fluge Vindedal, Øivind Skare, and Erlend A. Nagelhus. 2014. "Evidence That Pericytes Regulate Aquaporin-4 Polarization in Mouse Cortical Astrocytes." Brain Structure and Function 219 (6): 2181-86. https://doi.org/10.1007/S00429-013-0629-0.

He, Danyang, Jincheng Wang, Yulan Lu, Yaqi Deng, Chuntao Zhao, Lingli Xu, Yinhuai Chen, Yueh Chiang Hu, Wenhao Zhou, and Q Richard Lu. 2017. “LncRNA Functional Networks in Oligodendrocytes Reveal Stage-Specific Myelination Control by an LncOL1/Suz12 Complex in the CNS." Neuron 93 (2): 362-78. https://doi.org/10.1016/j.neuron.2016.11.044.

Hrvatin, Sinisa, Daniel R. Hochbaum, M. Aurel Nagy, Marcelo Cicconet, Keiramarie Robertson, Lucas Cheadle, Rapolas Zilionis, et al. 2018. "Single-Cell Analysis of Experience-Dependent Transcriptomic States in the Mouse Visual Cortex." Nature Neuroscience 21 (1): 120-29. https://doi.org/10.1038/s41593018-0112-6.

Hughes, Ethan G., Shin H. Kang, Masahiro Fukaya, and Dwight E. Bergles. 2013. "Oligodendrocyte Progenitors Balance Growth with Self-Repulsion to Achieve Homeostasis in the Adult Brain." Nature 
bioRxiv preprint doi: https://doi.org/10.1101/2021.11.09.467933; this version posted November 9, 2021. The copyright holder for this preprint (which was not certified by peer review) is the author/funder, who has granted bioRxiv a license to display the preprint in perpetuity. It is made available under aCC-BY-NC-ND 4.0 International license.

Neuroscience 16 (6): 668-76. https://doi.org/10.1038/nn.3390.

Hughes, Ethan G., Jennifer L. Orthmann-Murphy, Abraham J. Langseth, and Dwight E. Bergles. 2018. "Myelin Remodeling through Experience-Dependent Oligodendrogenesis in the Adult Somatosensory Cortex." Nature Neuroscience 21 (5): 696-706. https://doi.org/10.1038/s41593-018-0121-5.

Humphrey, Jack, Warren Emmett, Pietro Fratta, Adrian M. Isaacs, and Vincent Plagnol. 2017. "Quantitative Analysis of Cryptic Splicing Associated with TDP-43 Depletion.” BMC Medical Genomics 10 (1). https://doi.org/10.1186/s12920-017-0274-1.

Iguchi, Yohei, Masahisa Katsuno, Jun-ichi Niwa, Shinnosuke Takagi, Shinsuke Ishigaki, Kensuke Ikenaka, Kaori Kawai, et al. 2013. "Loss of TDP-43 Causes Age-Dependent Progressive Motor Neuron

Degeneration." Brain : A Journal of Neurology 136 (Pt 5): 1371-82.

https://doi.org/10.1093/BRAIN/AWT029.

Ince, Paul G., J. Robin Highley, Janine Kirby, Stephen B. Wharton, Hitoshi Takahashi, Michael J. Strong, and Pamela J. Shaw. 2011. "Molecular Pathology and Genetic Advances in Amyotrophic Lateral Sclerosis: An Emerging Molecular Pathway and the Significance of Glial Pathology." Acta Neuropathologica 122 (6): 657-71. https://doi.org/10.1007/s00401-011-0913-0.

Jeong, Yun Ha, Jonathan P. Ling, Sophie Z. Lin, Aneesh N. Donde, Kerstin E. Braunstein, Elisa Majounie, Bryan J. Traynor, Katherine D. LaClair, Thomas E. Lloyd, and Philip C. Wong. 2017. "Tdp-43 Cryptic Exons Are Highly Variable between Cell Types." Molecular Neurodegeneration 12 (1). https://doi.org/10.1186/s13024-016-0144-x.

Kang, Shin H., Masahiro Fukaya, Jason K. Yang, Jeffrey D. Rothstein, and Dwight E. Bergles. 2010. "NG2+ CNS Glial Progenitors Remain Committed to the Oligodendrocyte Lineage in Postnatal Life and Following Neurodegeneration." Neuron 68 (4): 668-81. https://doi.org/10.1016/j.neuron.2010.09.009.

Kang, Shin H., Ying Li, Masahiro Fukaya, Ileana Lorenzini, Don W. Cleveland, Lyle W. Ostrow, Jeffrey D. Rothstein, and Dwight E. Bergles. 2013. “Degeneration and Impaired Regeneration of Gray Matter Oligodendrocytes in Amyotrophic Lateral Sclerosis." Nature Neuroscience 16 (5): 571-79. https://doi.org/10.1038/nn.3357.

Kapeli, Katannya, Fernando J. Martinez, and Gene W. Yeo. 2017. "Genetic Mutations in RNA-Binding Proteins 
bioRxiv preprint doi: https://doi.org/10.1101/2021.11.09.467933; this version posted November 9, 2021. The copyright holder for this preprint (which was not certified by peer review) is the author/funder, who has granted bioRxiv a license to display the preprint in perpetuity. It is made available under aCC-BY-NC-ND 4.0 International license.

and Their Roles in ALS." Human Genetics. Springer Verlag. https://doi.org/10.1007/s00439-017-1830-7.

Kirby, Brandon B, Norio Takada, Andrew J Latimer, Jimann Shin, Thomas J Carney, Robert N Kelsh, and Bruce Appel. 2006. "In Vivo Time-Lapse Imaging Shows Dynamic Oligodendrocyte Progenitor Behavior during Zebrafish Development" 9. https://doi.org/10.1038/nn1803.

Lappe-Siefke, Corinna, Sandra Goebbels, Michel Gravel, Eva Nicksch, John Lee, Peter E Braun, lan R Griffiths, and Klaus-Armin Nave. 2003. "Disruption of Cnp1 Uncouples Oligodendroglial Functions in Axonal Support and Myelination." Nature Genetics 33 (3): 366-74.

https://pubmed.ncbi.nlm.nih.gov/12590258/.

Larson, Valerie A., Yevgeniya Mironova, Kimberly G. Vanderpool, Ari Waisman, John E. Rash, Amit Agarwal, and Dwight E. Bergles. 2018. "Oligodendrocytes Control Potassium Accumulation in White Matter and Seizure Susceptibility." ELife 7 (March): 1-33. https://doi.org/10.7554/eLife.34829.

Lee, Edward B., Virginia M.-Y. Lee, and John Q. Trojanowski. 2011. “Gains or Losses: Molecular Mechanisms of TDP43-Mediated Neurodegeneration." Nature Reviews Neuroscience 2011 13:1 13 (1): 38-50. https://doi.org/10.1038/nrn3121.

Lee, Hyunpil, Stetson Thacker, Nicholas Sarn, Ranjan Dutta, and Charis Eng. 2019. "Constitutional Mislocalization of Pten Drives Precocious Maturation in Oligodendrocytes and Aberrant Myelination in Model of Autism Spectrum Disorder." Translational Psychiatry 9 (1): 13. https://doi.org/10.1038/s41398018-0364-7.

Lee, Seonok, Michelle K. Leach, Stephanie A. Redmond, S. Y.Christin Christin Chong, Synthia H. Mellon, Samuel J. Tuck, Zhang Qi Feng, Joseph M. Corey, and Jonah R. Chan. 2012. "A Culture System to Study Oligodendrocyte Myelination Processes Using Engineered Nanofibers." Nature Methods 9 (9): 917-22. https://doi.org/10.1038/nmeth.2105.

Lieu, Christopher A., Shankar J. Chinta, Anand Rane, and Julie K. Andersen. 2013. "Age-Related Behavioral Phenotype of an Astrocytic Monoamine Oxidase-B Transgenic Mouse Model of Parkinson's Disease." PLoS ONE 8 (1). https://doi.org/10.1371/JOURNAL.PONE.0054200.

Ling, Jonathan P., Olga Pletnikova, Juan C. Troncoso, and Philip C. Wong. 2015. "TDP-43 Repression of Nonconserved Cryptic Exons Is Compromised in ALS-FTD." Science 349 (6248): 650-55. 
bioRxiv preprint doi: https://doi.org/10.1101/2021.11.09.467933; this version posted November 9, 2021. The copyright holder for this preprint (which was not certified by peer review) is the author/funder, who has granted bioRxiv a license to display the preprint in perpetuity. It is made available under aCC-BY-NC-ND 4.0 International license.

https://doi.org/10.1126/science.aab0983.

Ling, Shuo-Chien, Claudio P. Albuquerque, Joo Seok Han, Clotilde Lagier-Tourenne, Seiya Tokunaga, Huilin Zhou, and Don W. Cleveland. 2010. "ALS-Associated Mutations in TDP-43 Increase Its Stability and Promote TDP-43 Complexes with FUS/TLS." Proceedings of the National Academy of Sciences 107 (30): 13318-23. https://doi.org/10.1073/PNAS.1008227107.

Ma, X. Rosa, Mercedes Prudencio, Yuka Koike, Sarat C. Vatsavayai, Garam Kim, Fred Harbinski, Caitlin M. Rodriguez, et al. 2021. "TDP-43 Represses Cryptic Exon Inclusion in FTD/ALS Gene UNC13A.” BioRxiv, April, 2021.04.02.438213. https://doi.org/10.1101/2021.04.02.438213.

Marques, Sueli, Amit Zeisel, Simone Codeluppi, David Van Bruggen, Ana Mendanha Falcão, Lin Xiao, Huiliang $\mathrm{Li}$, et al. 2016. "Oligodendrocyte Heterogeneity in the Mouse Juvenile and Adult Central Nervous System." Science 352 (6291): 1326-29. https://doi.org/10.1126/science.aaf6463.

Masaki, Katsuhisa, Yoshifumi Sonobe, Ghanashyam Ghadge, Peter Pytel, Paula Lépine, Florian Pernin, Qiao Ling Cui, et al. 2020. "RNA-Binding Protein Altered Expression and Mislocalization in MS." Neurology(R) Neuroimmunology \{|\&\} Neuroinflammation 7 (3): 704. https://doi.org/10.1212/NXI.0000000000000704. Mei, Feng, S. Y. Christin Chong, and Jonah R. Chan. 2013. "Myelin-Based Inhibitors of Oligodendrocyte Myelination: Clues from Axonal Growth and Regeneration." Neuroscience Bulletin. https://doi.org/10.1007/s12264-013-1319-x.

Müller, Christina, Nina Marita Bauer, Isabelle Schäfer, and Robin White. 2013. "Making Myelin Basic Protein from MRNA Transport to Localized Translation." Frontiers in Cellular Neuroscience 0 (SEP): 169. https://doi.org/10.3389/FNCEL.2013.00169.

Neely, Sarah, Jill Williamson, Anna Klingseisen, Lida Zoupi, Jason Early, Anna Williams, and David Lyons. 2020. "New Oligodendrocytes Exhibit More Abundant and Accurate Myelin Regeneration than Those That Survive Demyelination." BioRxiv, May, 2020.05.22.110551. https://doi.org/10.1101/2020.05.22.110551. Neumann, Manuela, Deepak M. Sampathu, Linda K. Kwong, Adam C. Truax, Matthew C. Micsenyi, Thomas T. Chou, Jennifer Bruce, et al. 2006. “Ubiquitinated TDP-43 in Frontotemporal Lobar Degeneration and Amyotrophic Lateral Sclerosis." Science 314 (5796): 130-33. https://doi.org/10.1126/science.1134108. Oluich, Laura-Jane, Jo Anne S. Stratton, Yao Lulu Xing, Sze Woei Ng, Holly S. Cate, Pankaj Sah, François 
bioRxiv preprint doi: https://doi.org/10.1101/2021.11.09.467933; this version posted November 9, 2021. The copyright holder for this preprint (which was not certified by peer review) is the author/funder, who has granted bioRxiv a license to display the preprint in perpetuity. It is made available under aCC-BY-NC-ND 4.0 International license.

Windels, Trevor J. Kilpatrick, and Tobias D. Merson. 2012. "Targeted Ablation of Oligodendrocytes Induces Axonal Pathology Independent of Overt Demyelination." Journal of Neuroscience 32 (24): 831730. https://doi.org/10.1523/JNEUROSCI.1053-12.2012.

Orthmann-Murphy, Jennifer, Cody L Call, Gian Carlo Molina-Castro, Yu Chen Hsieh, Matthew N Rasband, Peter A Calabresi, and Dwight E Bergles. 2020. "Remyelination Alters the Pattern of Myelin in the Cerebral Cortex." ELife 9: 1-61. https://doi.org/10.7554/eLife.56621.

Paolicelli, Rosa C., Ali Jawaid, Christopher M. Henstridge, Andrea Valeri, Mario Merlini, John L. Robinson, Edward B. Lee, et al. 2017. "TDP-43 Depletion in Microglia Promotes Amyloid Clearance but Also Induces Synapse Loss." Neuron 95 (2): 297. https://doi.org/10.1016/J.NEURON.2017.05.037.

Parslow, Adam, Albert Cardona, and Robert J Bryson-Richardson. 2014. "Sample Drift Correction Following 4D Confocal Time-Lapse Imaging." Journal of Visualized Experiments : JoVE, no. 86. https://doi.org/10.3791/51086.

Penderis, Jacques, Simon A. Shields, and Robin J. M. Franklin. 2003. "Impaired Remyelination and Depletion of Oligodendrocyte Progenitors Does Not Occur Following Repeated Episodes of Focal Demyelination in the Rat Central Nervous System." Brain 126 (6): 1382-91. https://doi.org/10.1093/BRAIN/AWG126.

Peng, Audrey Yi Tyan, Ira Agrawal, Wan Yun Ho, Yi-Chun Yen, Ashley J. Pinter, Jerry Liu, Qi Xuan Cheryl Phua, et al. 2020. "Loss of TDP-43 in Astrocytes Leads to Motor Deficits by Triggering A1-like Reactive Phenotype and Triglial Dysfunction." Proceedings of the National Academy of Sciences 117 (46): 202007806. https://doi.org/10.1073/pnas.2007806117.

Petasny, Mayra, Mercedes Bentata, Andrea Pawellek, Mai Baker, Gillian Kay, and Maayan Salton. 2021. "Splicing to Keep Cycling: The Importance of Pre-MRNA Splicing during the Cell Cycle." Trends in Genetics 37 (3): 266-78. https://doi.org/10.1016/J.TIG.2020.08.013.

Phan, BaDoi N., Joseph F. Bohlen, Brittany A. Davis, Zengyou Ye, Huei-Ying Chen, Brent Mayfield, Srinidhi Rao Sripathy, et al. 2020. "A Myelin-Related Transcriptomic Profile Is Shared by Pitt-Hopkins Syndrome Models and Human Autism Spectrum Disorder." Nature Neuroscience 2020 23:3 23 (3): 375-85. https://doi.org/10.1038/s41593-019-0578-x.

Philips, Thomas, Yevgeniya A. Mironova, Yan Jouroukhin, Jeannie Chew, Svetlana Vidensky, Mohamed H. 
bioRxiv preprint doi: https://doi.org/10.1101/2021.11.09.467933; this version posted November 9, 2021. The copyright holder for this preprint (which was not certified by peer review) is the author/funder, who has granted bioRxiv a license to display the preprint in perpetuity. It is made available under aCC-BY-NC-ND 4.0 International license.

Farah, Mikhail V. Pletnikov, Dwight E. Bergles, Brett M. Morrison, and Jeffrey D. Rothstein. 2021. "MCT1

Deletion in Oligodendrocyte Lineage Cells Causes Late-Onset Hypomyelination and Axonal

Degeneration." Cell Reports 34 (2): 108610. https://doi.org/10.1016/J.CELREP.2020.108610.

Purice, Maria D., and J. Paul Taylor. 2018. "Linking HnRNP Function to ALS and FTD Pathology." Frontiers in Neuroscience. Frontiers Media S.A. https://doi.org/10.3389/fnins.2018.00326.

Redmond, Stephanie A., Feng Mei, Yael Eshed-Eisenbach, Lindsay A. Osso, Dena Leshkowitz, Yun An A. Shen, Jeremy N. Kay, et al. 2016. "Somatodendritic Expression of JAM2 Inhibits Oligodendrocyte Myelination." Neuron 91 (4): 824-36. https://doi.org/10.1016/j.neuron.2016.07.021.

Rohan, Zdenek, Radoslav Matej, Robert Rusina, and Gabor G Kovacs. 2014. "Oligodendroglial Response in the Spinal Cord in TDP-43 Proteinopathy with Motor Neuron Involvement." Neuro-Degenerative Diseases 14 (3): 117-24. https://doi.org/10.1159/000362929.

Rosenberg, S S, E E Kelland, E Tokar, A R De La Torre, and J R Chan. 2008. "The Geometric and Spatial Constraints of the Microenvironment Induce Oligodendrocyte Differentiation." Proceedings of the National Academy of Sciences 105 (38): 14662-67. https://doi.org/10.1073/pnas.0805640105.

Salapa, Hannah E., Catherine Hutchinson, Bogdan F. Popescu, and Michael C. Levin. 2020. "Neuronal RNABinding Protein Dysfunction in Multiple Sclerosis Cortex." Annals of Clinical and Translational Neurology 7 (7): 1214-24. https://doi.org/10.1002/acn3.51103.

Schindelin, Johannes, Ignacio Arganda-Carreras, Erwin Frise, Verena Kaynig, Mark Longair, Tobias Pietzsch, Stephan Preibisch, et al. 2012. "Fiji: An Open-Source Platform for Biological-Image Analysis." Nat Methods 9 (7): 676-82.

Sephton, Chantelle F., Shannon K. Good, Stan Atkin, Colleen M. Dewey, Paul Mayer, Joachim Herz, and Gang Yu. 2010. “TDP-43 Is a Developmentally Regulated Protein Essential for Early Embryonic Development." Journal of Biological Chemistry 285 (9): 6826-34.

https://doi.org/10.1074/jbc.M109.061846.

Sousa, Vitor H, Goichi Miyoshi, Jens Hjerling-Leffler, Theofanis Karayannis, and Gord Fishell. 2009.

“Characterization of Nkx6-2-Derived Neocortical Interneuron Lineages." Cerebral Cortex (New York, N.Y. : 1991) 19 Suppl 1 (Suppl 1). https://doi.org/10.1093/CERCOR/BHP038. 
bioRxiv preprint doi: https://doi.org/10.1101/2021.11.09.467933; this version posted November 9, 2021. The copyright holder for this preprint (which was not certified by peer review) is the author/funder, who has granted bioRxiv a license to display the preprint in perpetuity. It is made available under aCC-BY-NC-ND 4.0 International license.

Sun, Mingkuan, William Bell, Katherine D. LaClair, Jonathan P. Ling, Heather Han, Yusuke Kageyama, Olga

Pletnikova, Juan C. Troncoso, Philip C. Wong, and Liam L. Chen. 2017. "Cryptic Exon Incorporation

Occurs in Alzheimer's Brain Lacking TDP-43 Inclusion but Exhibiting Nuclear Clearance of TDP-43.” Acta Neuropathologica 133 (6): 923-31. https://doi.org/10.1007/s00401-017-1701-2.

Traka, Maria, Joseph R Podojil, Derrick P Mccarthy, Stephen D Miller, and Brian Popko. 2015.

"Oligodendrocyte Death Results in Immune-Mediated CNS Demyelination." Nature Neuroscience 19 (1):

65-74. https://doi.org/10.1038/nn.4193.

Tripathi, Richa B., Martyna Jackiewicz, Ian A. McKenzie, Eleni Kougioumtzidou, Matthew Grist, and William D.

Richardson. 2017. "Remarkable Stability of Myelinating Oligodendrocytes in Mice." Cell Reports 21 (2):

316-23. https://doi.org/10.1016/j.celrep.2017.09.050.

Viganò, Francesca, Wiebke Möbius, Magdalena Götz, and Leda Dimou. 2013. “Transplantation Reveals Regional Differences in Oligodendrocyte Differentiation in the Adult Brain." Nature Neuroscience 16 (10): 1370-72. https://doi.org/10.1038/nn.3503.

Walker, Adam K., Christine M. LaPash Daniels, James E. Goldman, John Q. Trojanowski, Virginia M.-Y. Lee, and Albee Messing. 2014. "Astrocytic TDP-43 Pathology in Alexander Disease.” Journal of Neuroscience 34 (19): 6448-58. https://doi.org/10.1523/JNEUROSCI.0248-14.2014.

Wang, Jia, Wan Yun Ho, Kenneth Lim, Jia Feng, Greg Tucker-kellogg, Klaus-armin Armin Nave, Shuo-chien Chien Ling, et al. 2018. "Cell-Autonomous Requirement of TDP-43, an ALS/FTD Signature Protein, for Oligodendrocyte Survival and Myelination." Proceedings of the National Academy of Sciences of the United States of America 115 (46): E10941-50. https://doi.org/10.1073/pnas.1809821115.

Wang, Shan, Tao Wang, Tao Liu, Rou-Gang Xie, Xiang-Hui Zhao, Lei Wang, Qian Yang, Lin-Tao Jia, and Jing Han. 2020. “Ermin Is a P116 RIP -Interacting Protein Promoting Oligodendroglial Differentiation and Myelin Maintenance." Glia 68 (11): 2264-76. https://doi.org/10.1002/GLIA.23838.

Warraich, Sadaf T, Shu Yang, Garth A Nicholson, and lan P Blair. 2010. "TDP-43: A DNA and RNA Binding Protein with Roles in Neurodegenerative Diseases." The International Journal of Biochemistry \& Cell Biology 42 (10): 1606-9. https://doi.org/10.1016/J.BIOCEL.2010.06.016.

Weil, Marie-Theres, Torben Ruhwedel, Martin Meschkat, Boguslawa Sadowski, and Wiebke Möbius. 2019. 
bioRxiv preprint doi: https://doi.org/10.1101/2021.11.09.467933; this version posted November 9, 2021. The copyright holder for this preprint (which was not certified by peer review) is the author/funder, who has granted bioRxiv a license to display the preprint in perpetuity. It is made available under aCC-BY-NC-ND 4.0 International license.

"Transmission Electron Microscopy of Oligodendrocytes and Myelin." Methods Mol Biol., no. 1936: 34375.

Wiesner, Diana, Lilla Tar, Birgit Linkus, Akila Chandrasekar, Florian olde Heuvel, Luc Dupuis, William Tsao, Philip C. Wong, Albert Ludolph, and Francesco Roselli. 2018. "Reversible Induction of TDP-43 Granules in Cortical Neurons after Traumatic Injury." Experimental Neurology 299 (Pt A): 15-25. https://doi.org/10.1016/j.expneurol.2017.09.011.

Wong, Margaret, and Lee J. Martin. 2010. "Skeletal Muscle-Restricted Expression of Human SOD1 Causes Motor Neuron Degeneration in Transgenic Mice." Human Molecular Genetics 19 (11): 2284-2302. https://doi.org/10.1093/HMG/DDQ106.

Wu, Lien-Szu, Wei-Cheng Cheng, Chia-Ying Chen, Ming-Che Wu, Yi-Chi Wang, Yu-Hsiang Tseng, TreesJuen Chuang, and C.-K. James Shen. 2019. "Transcriptomopathies of Pre- and Post-Symptomatic Frontotemporal Dementia-like Mice with TDP-43 Depletion in Forebrain Neurons." Acta Neuropathologica Communications 2019 7:1 7 (1): 1-31. https://doi.org/10.1186/S40478-019-0674-X.

Xiao, Lin, David Ohayon, Ian A Mckenzie, Alexander Sinclair-Wilson, Jordan L Wright, Alexander D Fudge, Ben Emery, Huiliang Li, and William D Richardson. 2016. "Rapid Production of New Oligodendrocytes Is Required in the Earliest Stages of Motor-Skill Learning." Nature Neuroscience 19 (9): 1210-17. https://doi.org/10.1038/nn.4351.

Xing, Yao Lulu, Bernard H.A. Chuang, Jasmine Poh, Kaveh Moradi, Stanislaw Mitew, Trevor J. Kilpatrick, Yasuyuki Osanai, and Tobias D. Merson. 2021. "A Novel Pharmacogenetic Model for Highly Efficient Ablation of Oligodendrocyte Progenitor Cells in the Adult Mouse CNS." BioRxiv, May, 2021.05.13.443012. https://doi.org/10.1101/2021.05.13.443012.

Xu, Huan, Yulia Dzhashiashvili, Guo-Li Ming, Chuan He, and Brian Popko Correspondence. 2020. “M 6 A MRNA Methylation Is Essential for Oligodendrocyte Maturation and CNS Myelination." Neuron 105: 293309. https://doi.org/10.1016/j.neuron.2019.12.013.

Yang, Chunxing, Hongyan Wang, Tao Qiao, Bin Yang, Leonardo Aliaga, Linghua Qiu, Weijia Tan, et al. 2014. "Partial Loss of TDP-43 Function Causes Phenotypes of Amyotrophic Lateral Sclerosis." Proceedings of the National Academy of Sciences 111 (12): E1121-29. https://doi.org/10.1073/PNAS.1322641111. 
bioRxiv preprint doi: https://doi.org/10.1101/2021.11.09.467933; this version posted November 9, 2021. The copyright holder for this preprint (which was not certified by peer review) is the author/funder, who has granted bioRxiv a license to display the preprint in perpetuity. It is made available under aCC-BY-NC-ND 4.0 International license.

Zhang, Peisu, Yuki Kishimoto, Ioannis Grammatikakis, Kamalvishnu Gottimukkala, Roy G Cutler, Shiliang Zhang, Kotb Abdelmohsen, et al. 2019. "Senolytic Therapy Alleviates A $\beta$-Associated Oligodendrocyte Progenitor Cell Senescence and Cognitive Deficits in an Alzheimer's Disease Model.” Nature Neuroscience 22 (5): 719-28. https://doi.org/10.1038/S41593-019-0372-9.

Zhao, Weihua, David R. Beers, Shaughn Bell, Jinghong Wang, Shixiang Wen, Robert H. Baloh, and Stanley H. Appel. 2015. “TDP-43 Activates Microglia through NF-KB and NLRP3 Inflammasome.” Experimental Neurology 273 (November): 24-35. https://doi.org/10.1016/j.expneurol.2015.07.019.

Ziaei, Amin, Marta Garcia-Miralles, Carola I. Radulescu, Harwin Sidik, Aymeric Silvin, Han-Gyu Bae, Carine Bonnard, et al. 2020. "Ermin Deficiency as an Inside-out Model of Inflammatory Dysmyelination." BioRxiv, June, 2020.06.16.154781. https://doi.org/10.1101/2020.06.16.154781.

\section{Acknowledgements}

We thank M. Pucak at the Multiphoton Imaging (MPI) Core in the Department of Neuroscience at Johns Hopkins for technical assistance, E. Peles for gift of the mouse anti-Ermin primary antibody, M. Rasband for anti-BIV-spectrin primary antibody, M. Bhat for guinea pig anti-Caspr primary, and members of the Bergles lab for discussions. V. Doze assisted in quantifying the myelinated axons in TEM images, and C.L. Call generated a diagram for Figure 3-figure supplement 3B. D. Heo was supported by NINDS National Research Service Award (NRSA) predoctoral training fellowship (F31NS110204). G. C. Molina-Castro was supported by a National Science Foundation Graduate Research Fellowship (DGE-1746891). K-A. Nave was supported by an ERC Advanced Grant (MyeliNANO) and DFG-TRR274. Funding was provided by grants from The National MS Society, Target ALS and the Dr. Miriam and Sheldon G Adelson Medical Research Foundation to D.E. Bergles and K-A. Nave.

\section{Author Contributions}

D.H. and D.E.B. designed the experiments. D.H. executed and analyzed the experiments described in the figures and text. J.P.L. performed cryptic exon analysis on bulk RNA-Seq data and generated a table for Figure 6F. G.C.M-C performed myelin internode quantification for individual oligodendrocytes. A.J.L. generated Mobp- 

available under aCC-BY-NC-ND 4.0 International license.

919 iCre and Mobp-iCreER mousse lines and created Figure 2-figure supplement 1. A.W. provided Mog-iCre

920 mouse line for the study. W.M. performed TEM and provided guidance in quantifying g-ratio for Figure 4.

921 J.P.L., G.C.M-C, K-A.N., W.M., and P.C.W. provided comments on the manuscript that D.H. and D.E.B. wrote.

\section{Competing Interests statement}

924 The authors declare no competing financial interests.

Figures and legends

A
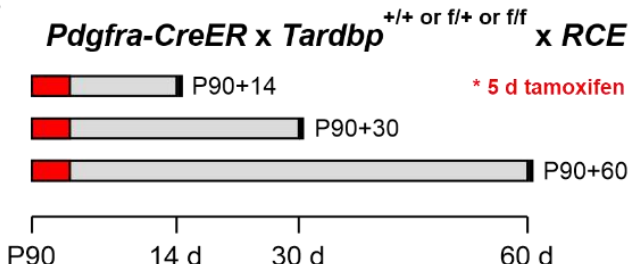

$P 90+60$

$$
\text { P90 }
$$

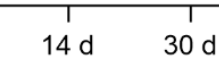

$60 \mathrm{~d}$

B
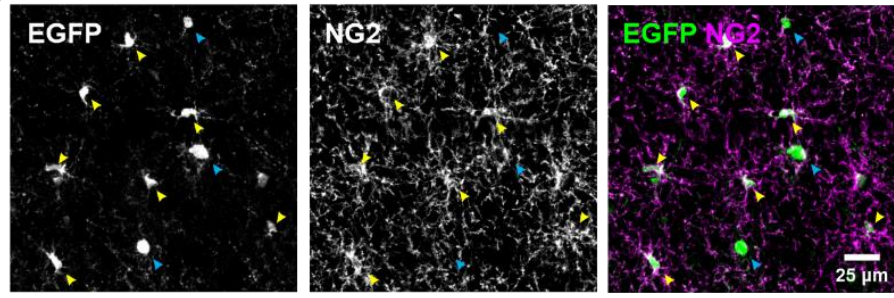

C
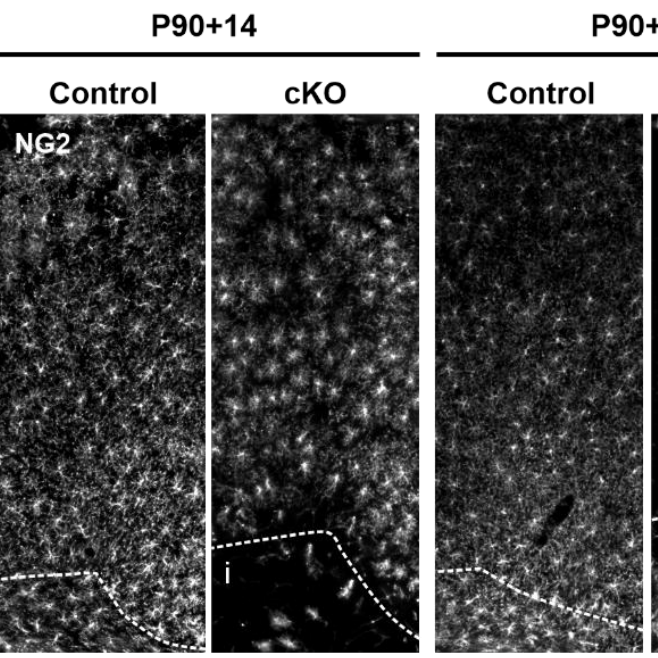

$\mathrm{P} 90+30$

cKO
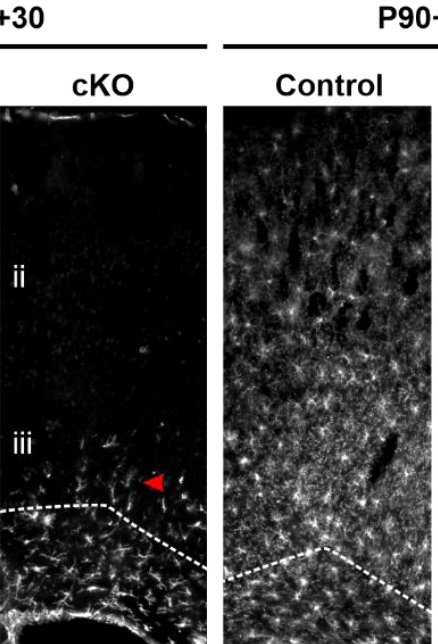

$90+60$

cKO

E

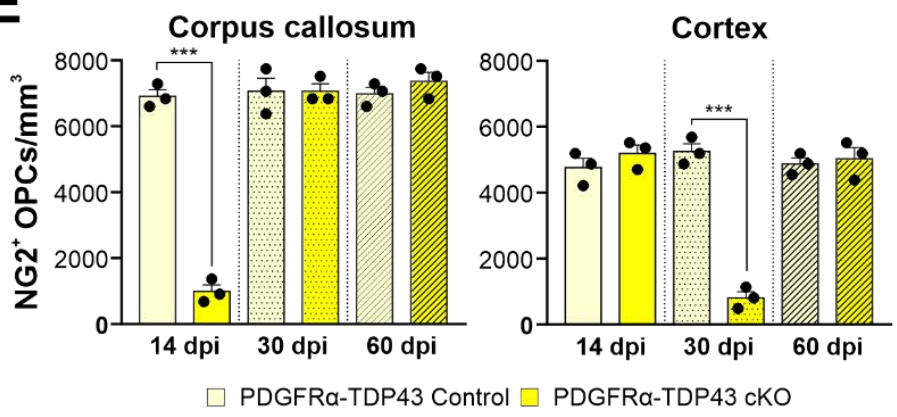

$\mathbf{F}$

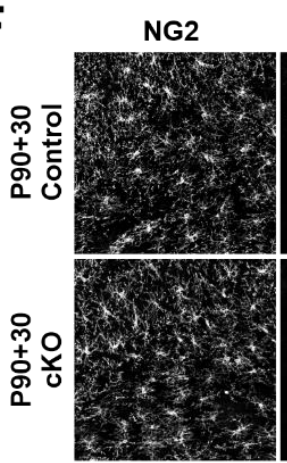

Ki-67

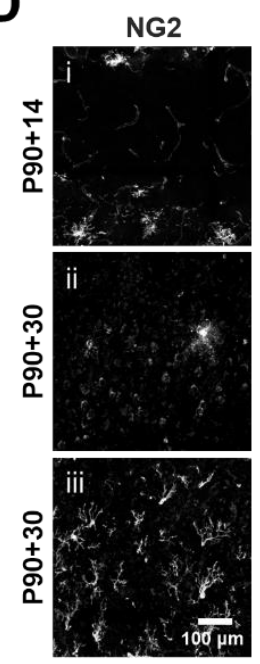

Figure 1 - OPCs require TDP-43 for survival. 
929 A. Schematics of CreER activation. At P90, tamoxifen was administered for 5 consecutive days. Tissue

samples were collected 14, 30, and 60 days after the last day of tamoxifen injection. B. Pdgfra-CreER;RCE

allows labeling of oligodendrocyte lineage cells. Yellow arrowheads indicate EGFP+NG2+ OPCs whereas blue arrowheads indicate EGFP+NG2- oligodendrocytes. C. NG2 staining shows that there is a regional progression in OPC degeneration from white matter to gray matter. The dotted line separates the corpus callosum from cortex. i, ii, iii regions are zoomed in in D. D. Region i shows the corpus callosum with a near complete loss of OPCs at P90+14. ii shows loss of OPCs in the cortex at P90+30. iii shows highly polarized OPCs migrating from the corpus callosum up to cortex. E. Quantification of NG2+ OPC density in corpus callosum and cortex at 14, 30, and 60 days post injection of tamoxifen (dpi). Statistical significance was determined using one-way ANOVA with Tukey's multiple comparisons test $\left(n=4,{ }^{* * *} p\right.$-value $<0.001$, n.s. $p$ -

939 value $>0.05)$. F. Ki-67+NG2+ proliferating OPCs increase in number at P90+60 in the corpus callosum of PDGFRa-TDP43 KO. 

available under aCC-BY-NC-ND 4.0 International license.

A

30 dpi Corpus callosum

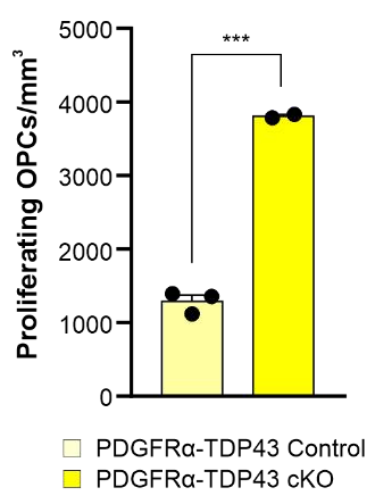

C

Pdgfra-CreER x Tardbp ${ }^{+/+}$or $\mathrm{f} /+$ or f/f

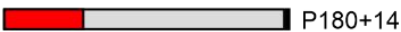

${ }^{*} 5 \mathrm{~d}$ tamoxifen

P180+14

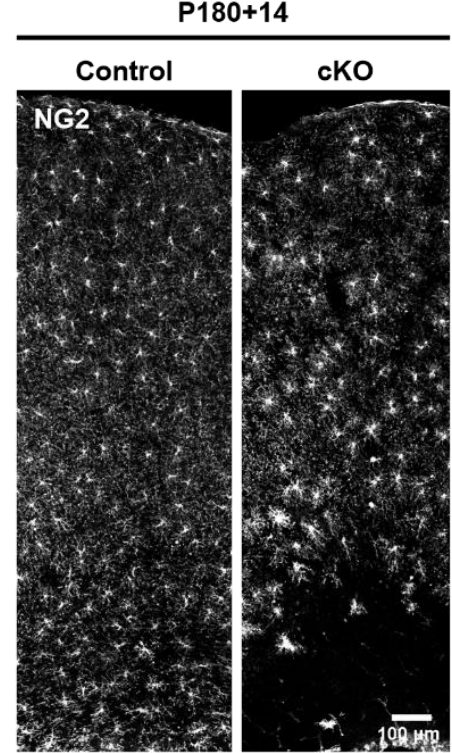

B

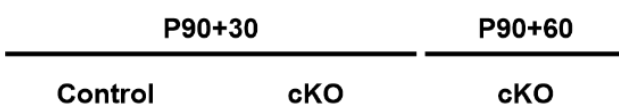

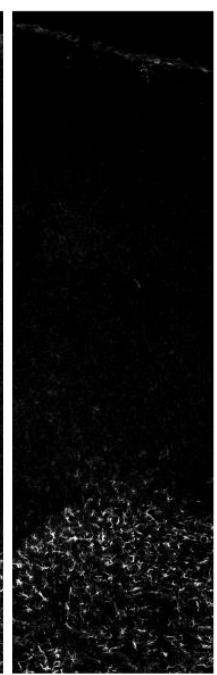

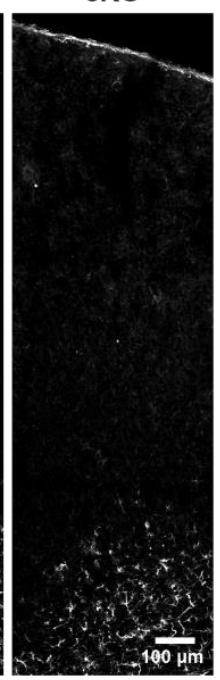

D

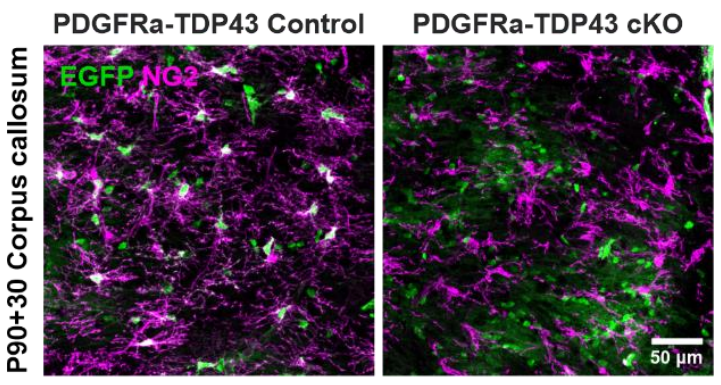

Figure 1-figure supplement 1 - PDGFRa-TDP43 cKO shows a regional difference in degeneration of OPCs.

A. Quantification of NG2+Ki-67+ proliferating OPCs in Figure 1F. (Unpaired, two-tailed Student's t-test, ${ }^{* * *} \mathrm{p}$ value $=0.0002, n=3,2)$. B. Coronal brain sections immunostained for GFAP at 30 and 60 days after tamoxifen TDP43 cKO induces OPC degeneration in the corpus callosum at $14 \mathrm{dpi}$ (similar to Figure 1E). D. Regenerated NG2+ OPCs at 30 dpi in PDGFRa-TDP43 cKO are negative for EGFP, suggesting that they have been repopulated by Cre- WT OPCs. 
A

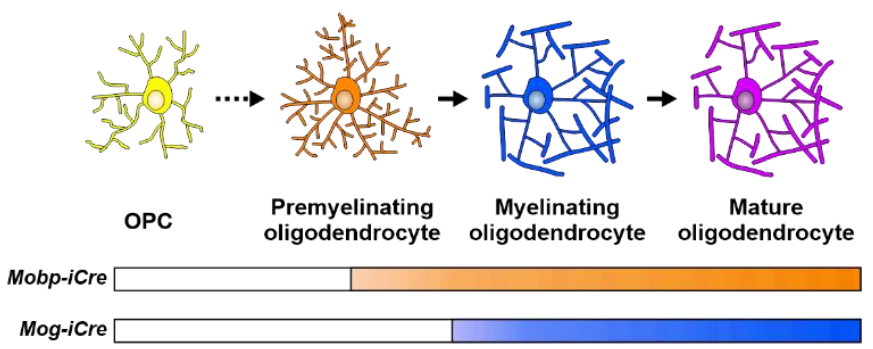

B

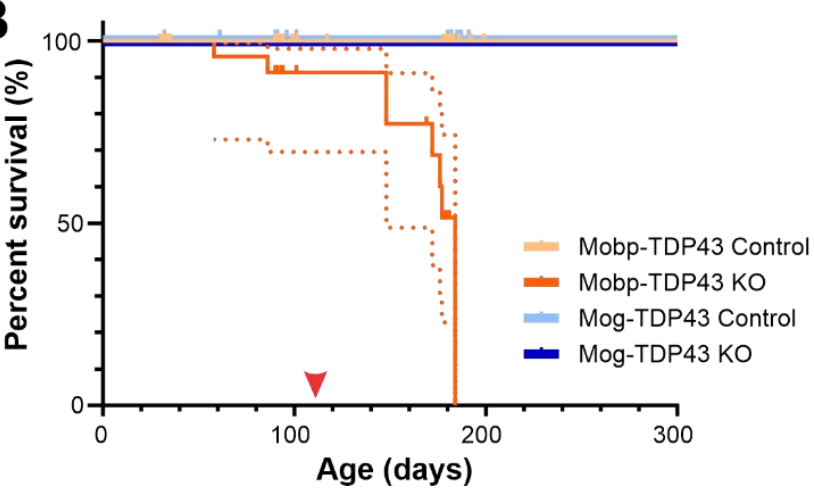

C P30 P90

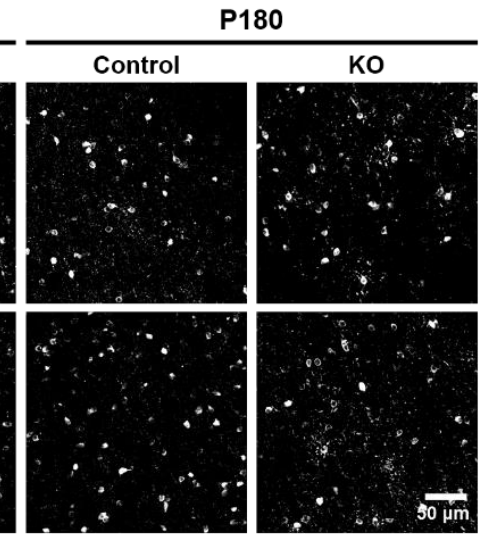

D
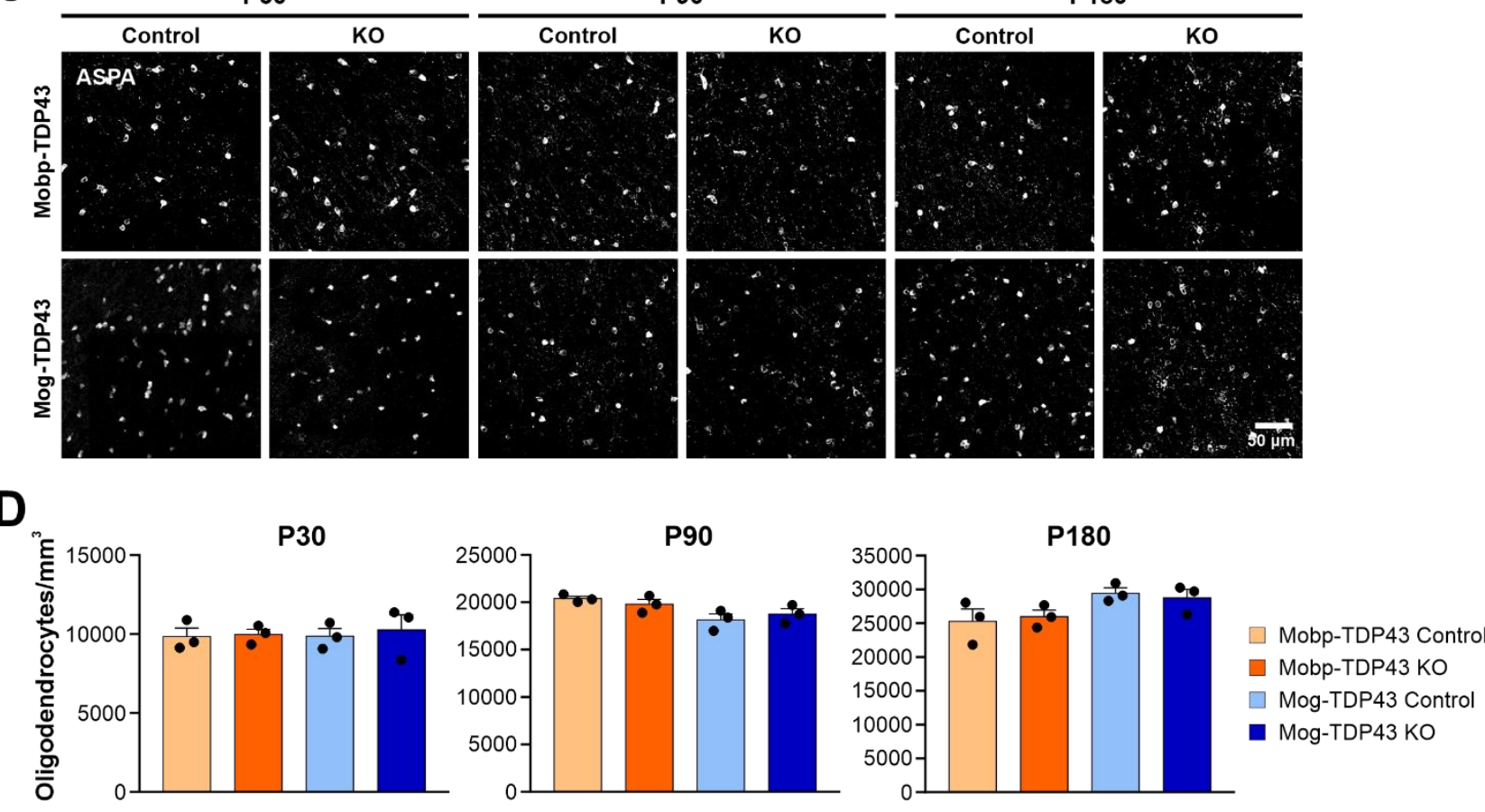

E

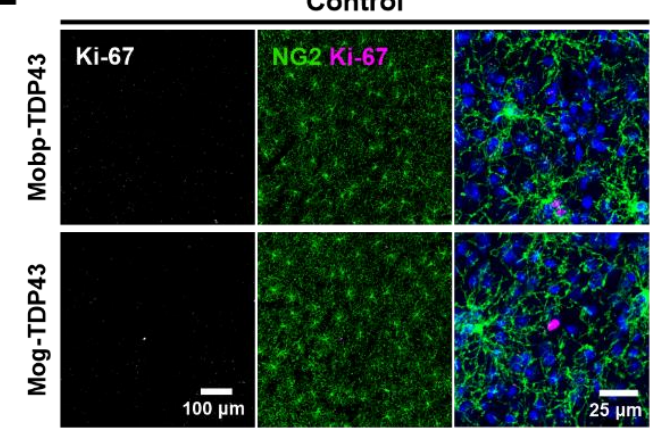

KO

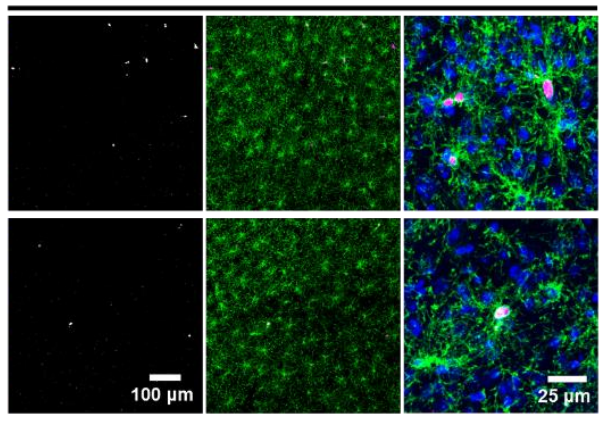

$\mathbf{F}$

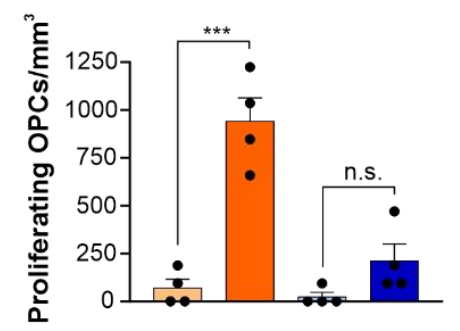

$\square$ Mobp-TDP43 Control $\square$ Mog-TDP43 Control Mobp-TDP43 KO a Mog-TDP43 KO

953 Figure 2 - Early deletion of TDP-43 in premyelinating oligodendrocytes leads to seizure development, premature death, and increased oligodendrocyte turnover. 
955 A. Diagram of oligodendrocyte development showing Mobp-iCre induces Tardbp deletion at the premyelinating

oligodendrocyte stage whereas Mog-iCre targets myelinating oligodendrocytes. B. Kaplan-Meier survival curve

957 for Mobp-TDP43 (orange) and Mog-TDP43 (blue) mouse lines. Dotted line indicates the 95\% confidence

958 interval. Log-rank (Mantel-Cox) statistical test showed significance at $p$-value $<0.0001(n=58,33,40,32)$. Red

959 arrowhead points to $\sim$ P110 when the animals first exhibit spontaneous seizures. C. ASPA+ oligodendrocyte

960 staining in the motor cortex of Mobp-TDP43 and MOG-TDP43 mouse lines at P30, P90, and P180. D.

961 Quantification of ASPA+ oligodendrocyte density shows that there is no statistical difference between the samples at any given timepoint (one-way ANOVA with Tukey's multiple comparisons test, $n=3, n$.s. $p$-value > 


\section{A} Mobp-iCreER lines x RCE

\begin{tabular}{ll}
\hline & $P 35$ \\
P35 & $+5 \mathrm{~d}$
\end{tabular}$*$ 3 d $100 \mathrm{mg} / \mathrm{kg}$ tamoxifen

B
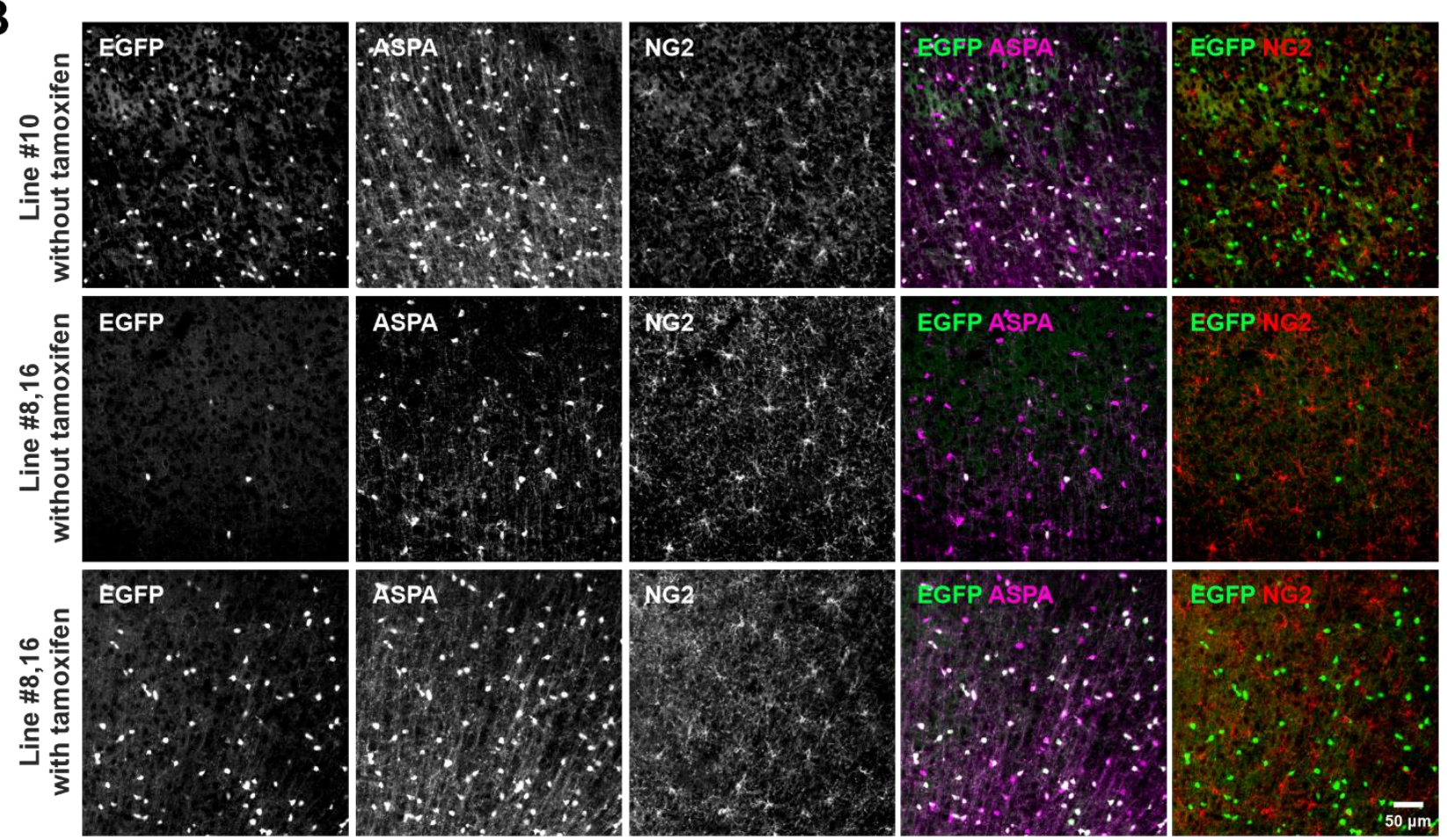

C
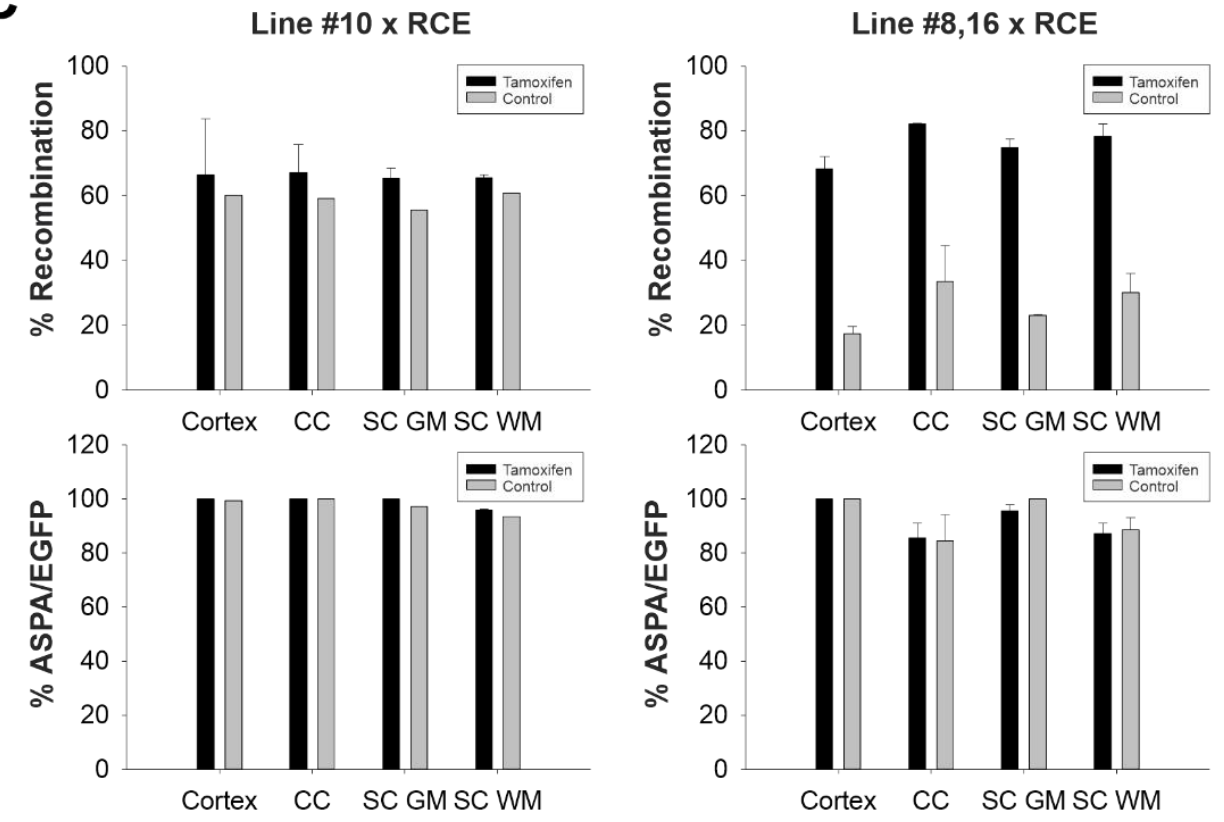

Figure 2-figure supplement 1 - Characterization of Mobp-iCre and Mobp-iCreER ${ }^{T 2}$ mouse lines.

A. Schematic of tamoxifen injection in different Mobp-iCreER mouse lines at P35. B. Representative images of 

available under aCC-BY-NC-ND 4.0 International license.

and without tamoxifen injections. C. Quantification of \% recombination (EGFP+ASAP+/ASPA+) and \%

ASPA+/EGFP+ to show recombination efficiency and specificity in Lines \#10 and \#8,16 in cortex, corpus

callosum (CC), spinal cord gray matter (SC GM), and spinal cord white matter (SC WM).

A

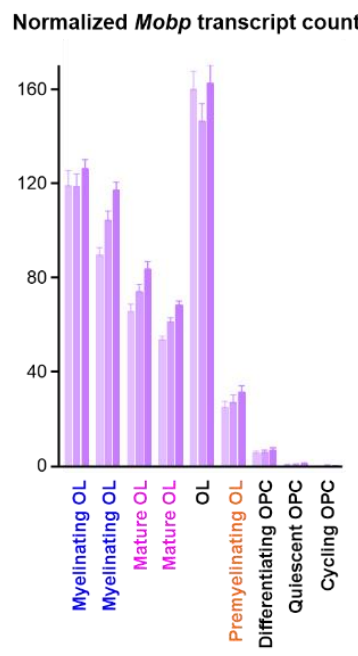

\section{B}

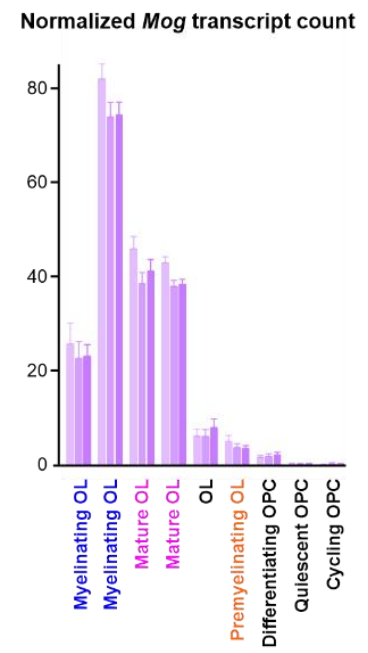

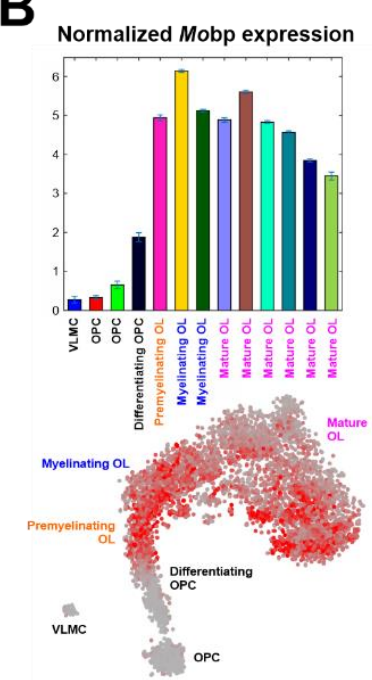

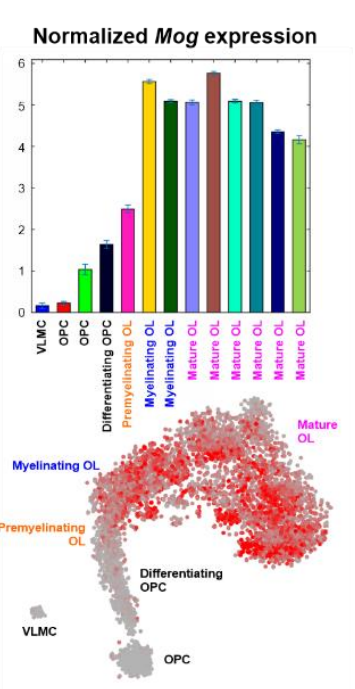

Figure 2-figure supplement 2 - Mobp-TDP43 and Mog-TDP43 mouse lines exhibit differences in response to loss of TDP-43.

A. Mobp and Mog expression in oligodendrocyte lineage cells (adapted from Hrvatin et al. (Hrvatin et al. 2018)). B. Mobp and Mog expression in the lineage of oligodendrocytes (adapted from Marques et al. (Marques et al. 2016)).
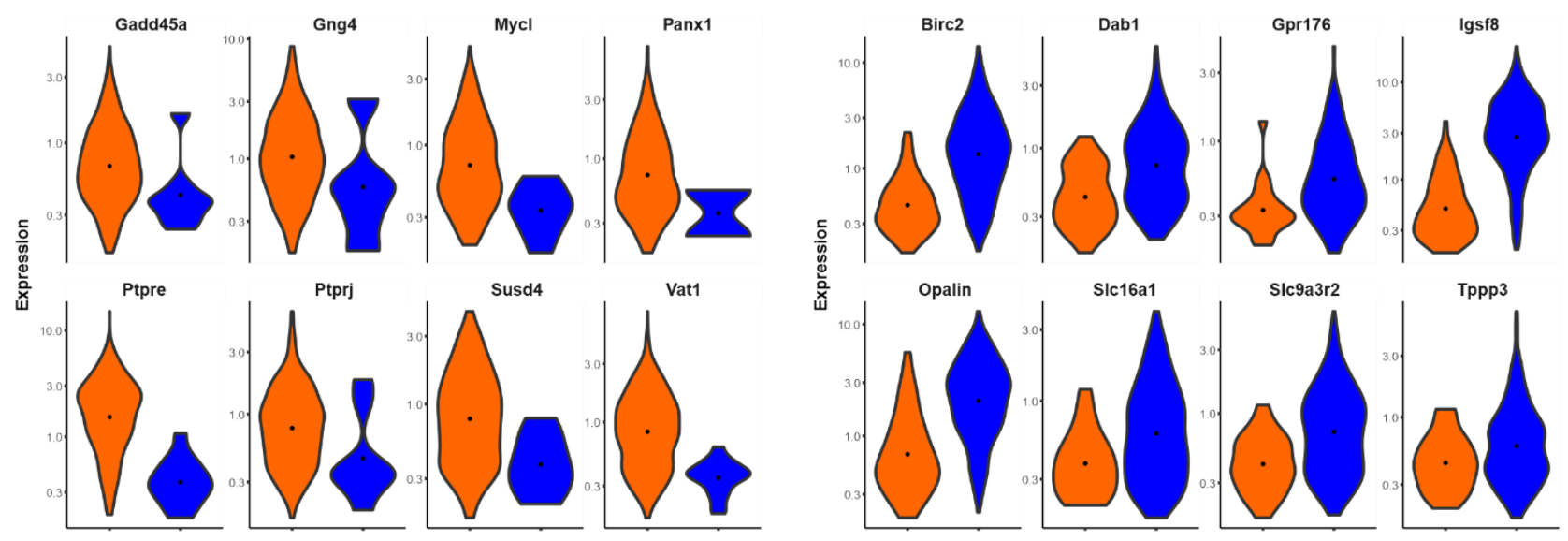

available under aCC-BY-NC-ND 4.0 International license.

984 Figure 2-figure supplement 3 - Differential gene expression between premyelinating (orange) and 985 myelinating (blue) oligodendrocytes (OL) (adapted from Hrvatin et al. (Hrvatin et al. 2018)). Top 16 differentially 986 expressed genes are shown. All genes are statistically significantly differentially expressed (q-value $<0.01)$.

A

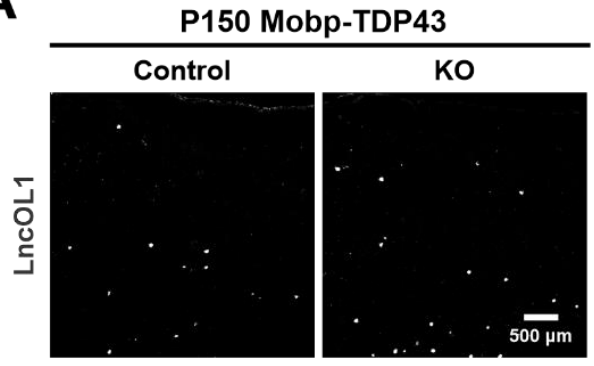

B
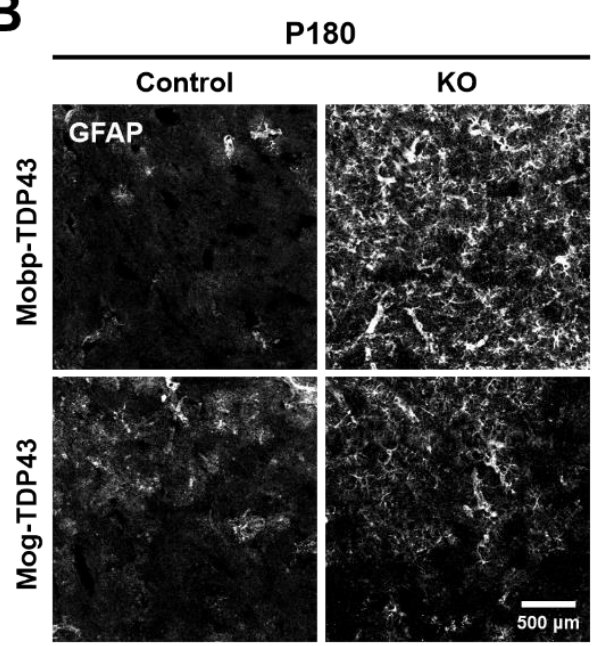

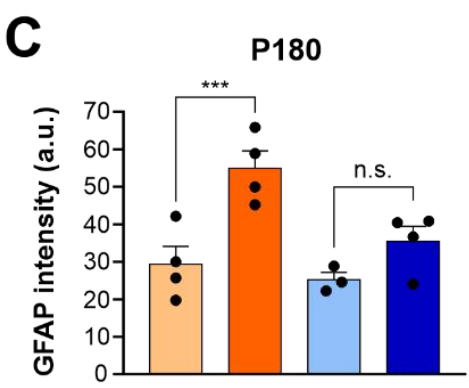

$\square$ Mobp-TDP43 Control $\square$ Mobp-TDP43 KO

$\square$ Mog-TDP43 Control

- Mog-TDP43 KO

\section{Figure 2-figure supplement 4}

A. In situ hybridization for IncOL1 (9630013A20Rik) shows increased number of premyelinating

oligodendrocytes in P150 Mobp-TDP43 KO compared to the Control. B. Immunostaining for GFAP in the motor cortex at P180 in Mobp-TDP43 and Mog-TDP43 mouse lines. Scale bar $=500 \mu \mathrm{m}$. C. Quantification of mean GFAP intensity (arbitrary unit; a.u.) in the motor cortex. One-way ANOVA with Tukey's multiple comparisons test, ${ }^{* * *} p$-value $<0.001$, n.s. $p$-value $>0.05$. 
bioRxiv preprint doi: https://doi.org/10.1101/2021.11.09.467933; this version posted November 9, 2021. The copyright holder for this preprint (which was not certified by peer review) is the author/funder, who has granted bioRxiv a license to display the preprint in perpetuity. It is made available under aCC-BY-NC-ND 4.0 International license.
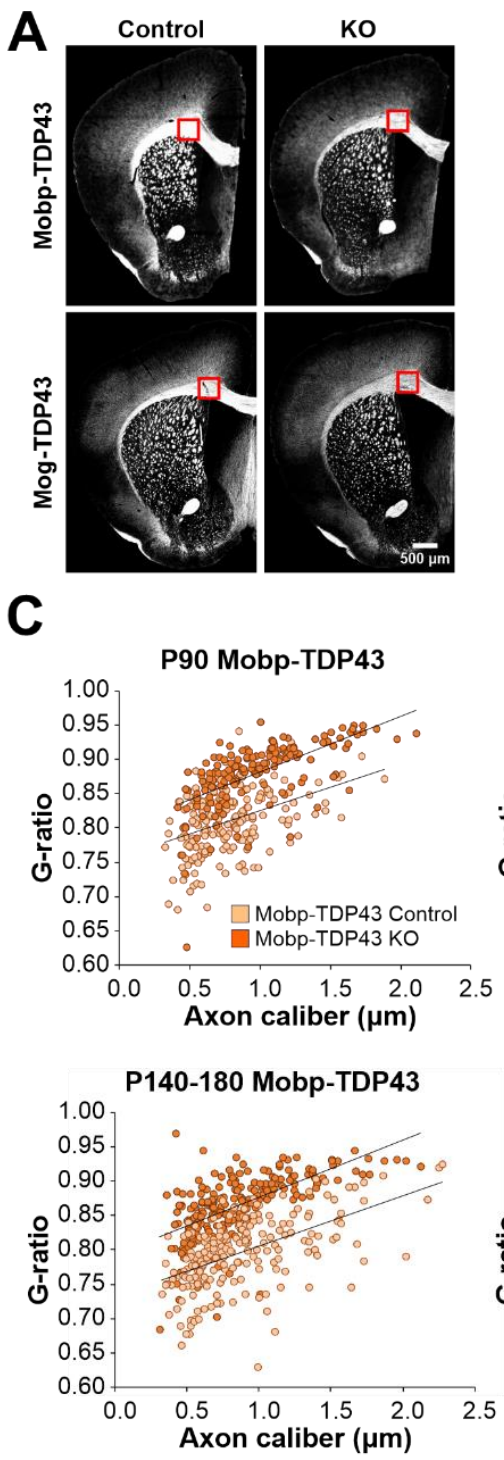

$\mathbf{E}$

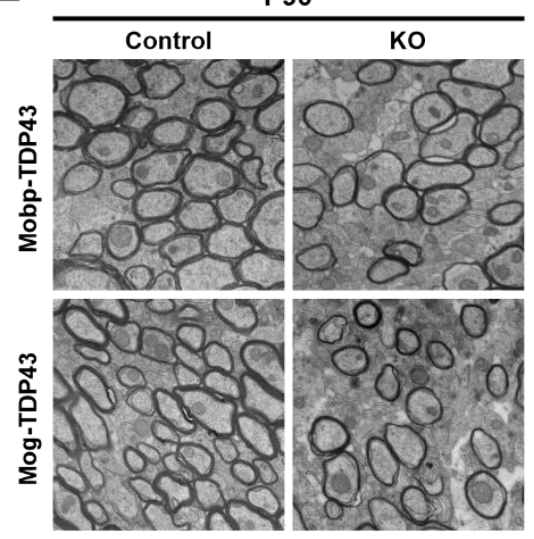

B
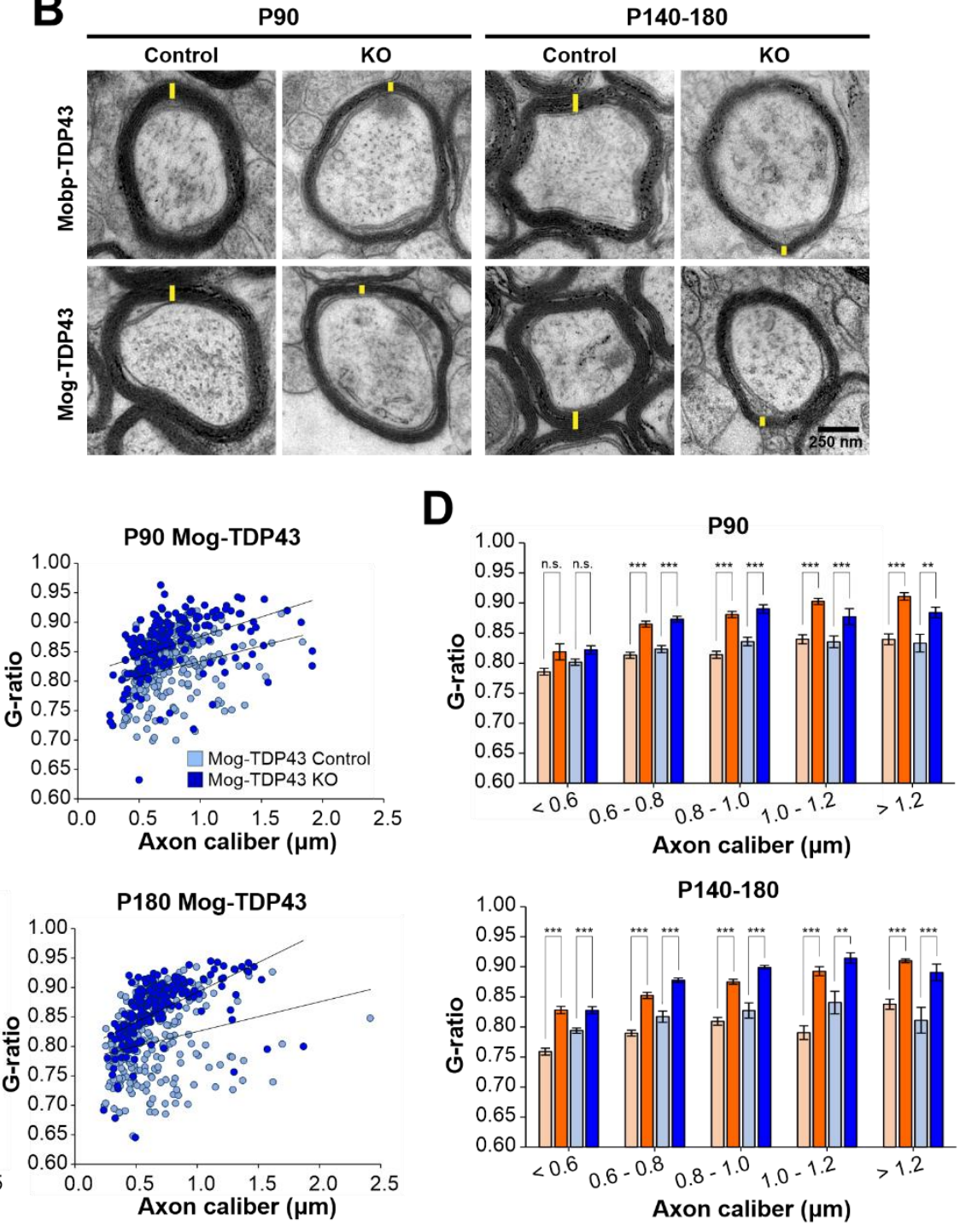

$\mathbf{F}$

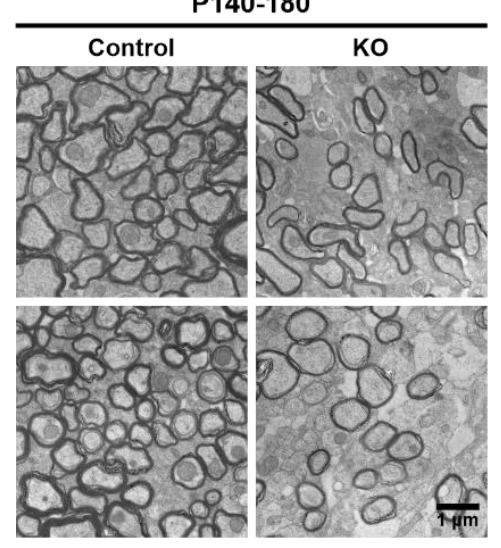

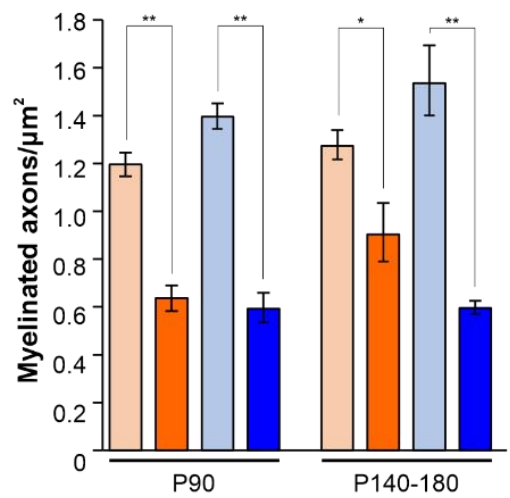

G Double myelination

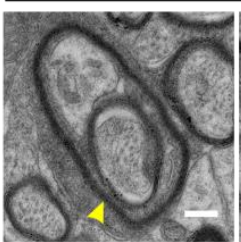

Organelle accumulation in myelin sheath
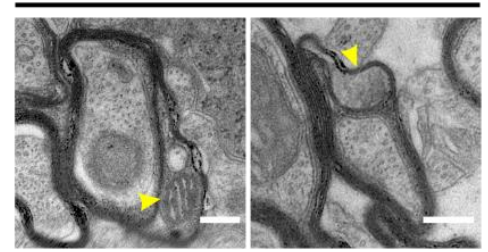

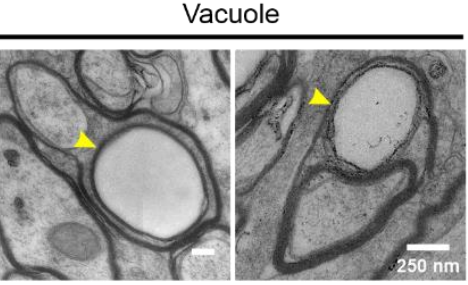


Figure 3 - Loss of TDP-43 oligodendrocytes leads to fewer and thinner myelin sheaths.

A. Tiled mouse brain coronal sections from P90 Mobp-TDP43 and Mog-TDP43 mouse lines immunostained

with MBP. Red box indicates where TEM was performed. B. Representative transmission electron micrographs of individual axon cross-sections from Mobp-TDP43 and Mog-TDP43 mouse lines at P90 and P140-180 show decreased myelin sheath thickness (yellow) in the KO. Scale bar $=250 \mathrm{~nm}$. C. G-ratios of individual myelinated axons as a function of axon caliber $(\mu \mathrm{m})$ in the corpus callosum of Mobp-TDP43 (orange) and Mog-TDP43 (blue) mouse lines at P90 and P140-180. n=3-4/genotype/timepoint. The solid lines show the lines of best fit with a linear function. D. Bar graphs of g-ratio values for individual axons in different bins of axon caliber $(\mu \mathrm{m})$. Statistical significance was determined using unpaired, two-tailed Student's t-test $\left({ }^{\star * *} p\right.$-value $<0.001,{ }^{\star *} p$ value $<0.01$, n.s. p-value $>0.05)$. E. Representative electron micrographs of Mobp-TDP43 and Mog-TDP43 mouse lines at P90 and P140-180 show a decreased density of myelinated axons in the KO. Scale bar $=1 \mu \mathrm{m}$ F. Quantification of myelinated axon density in Mobp-TDP43 (orange) and Mog-TDP43 (blue) mouse lines at P90 and P140-180. Statistical significance was determined using unpaired, two-tailed Student's t-test $\left({ }^{\star *} \mathrm{p}\right.$ value $<0.01,{ }^{*} p$-value $<0.05$, n.s. p-value $\left.>0.05\right)$. G. Examples of abnormal myelination from TEM at the ultrastructural level. Scale bar $=250 \mathrm{~nm}$. Yellow arrowheads indicate abnormal myelin structures.
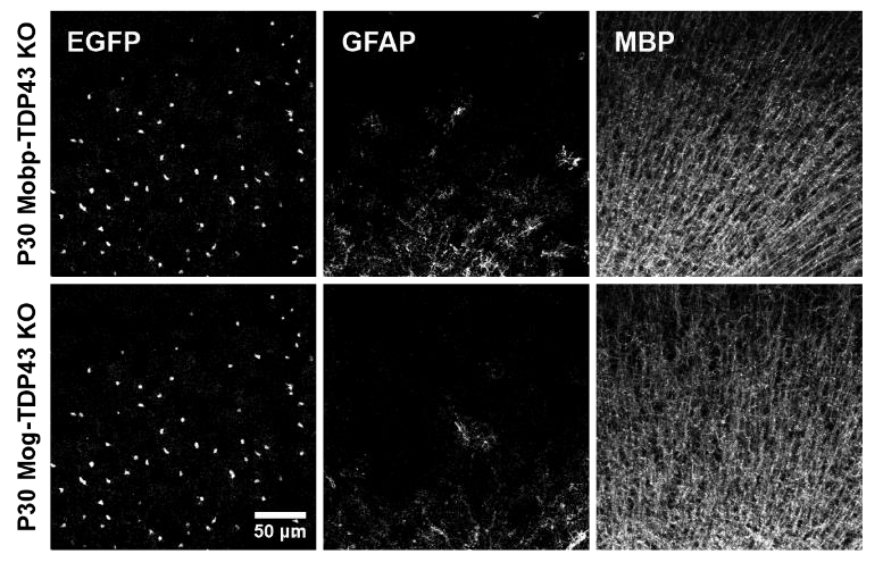

Figure 3-figure supplement 1 - Myelination and paranodal abnormalities with loss of TDP-43 in oligodendrocytes.

Immunostaining for GFP, GFAP, and MBP at P30 in Mobp-TDP43 and Mog-TDP43 mouse lines shows that oligodendrocytes and myelin are formed without astrogliosis. 


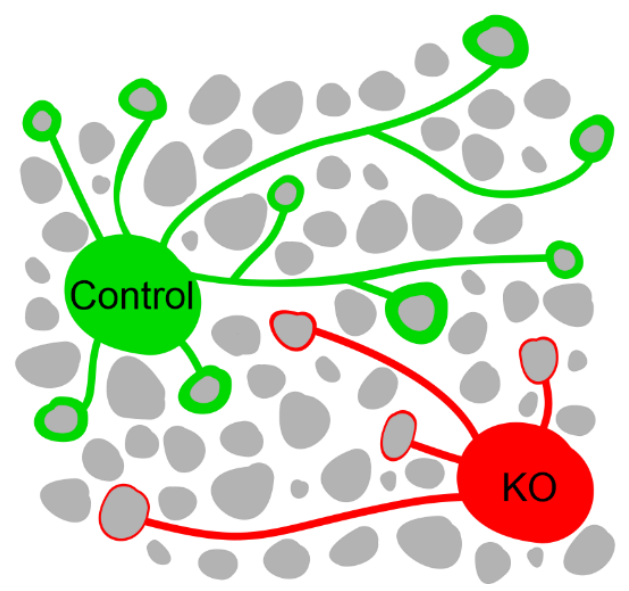

Figure 3-figure supplement 2 thinner myelin sheaths. 


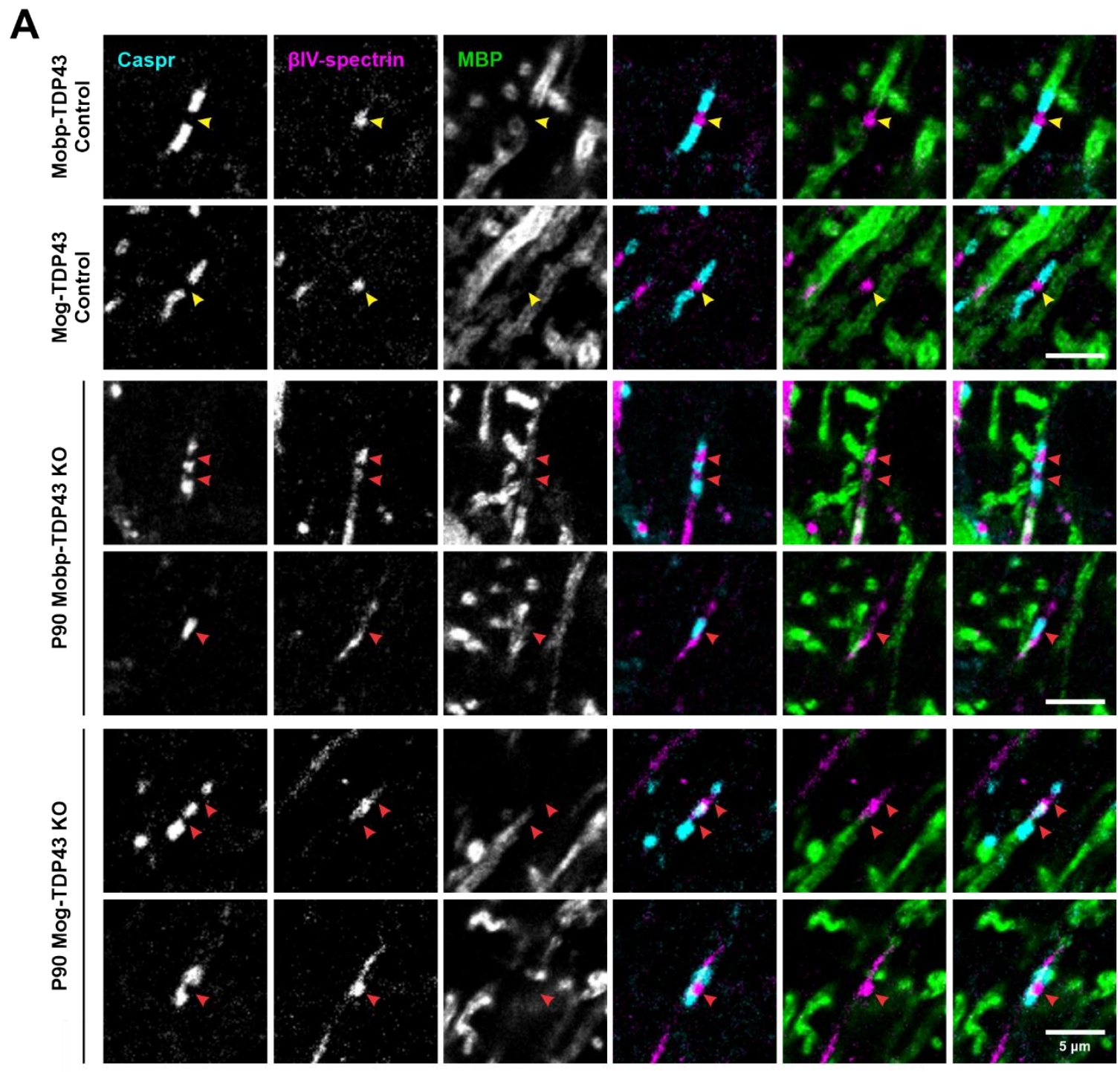

\section{B}

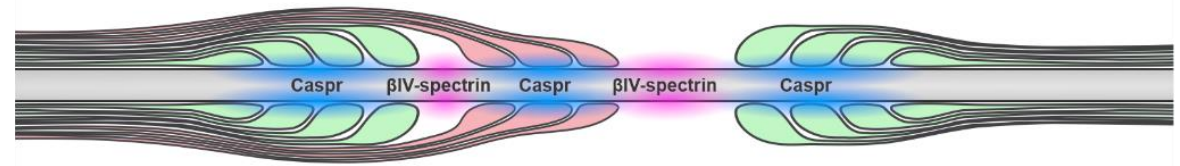

Figure 3-figure supplement 3

026 A. Examples of normal (yellow arrowheads) and abnormal (red arrowheads) nodal and paranodal proteins

027 (Caspr, $\beta \mathrm{IV}$-spectrin, and MBP) in Control and KO at P90. B. Diagram of double myelination by a KO 
A

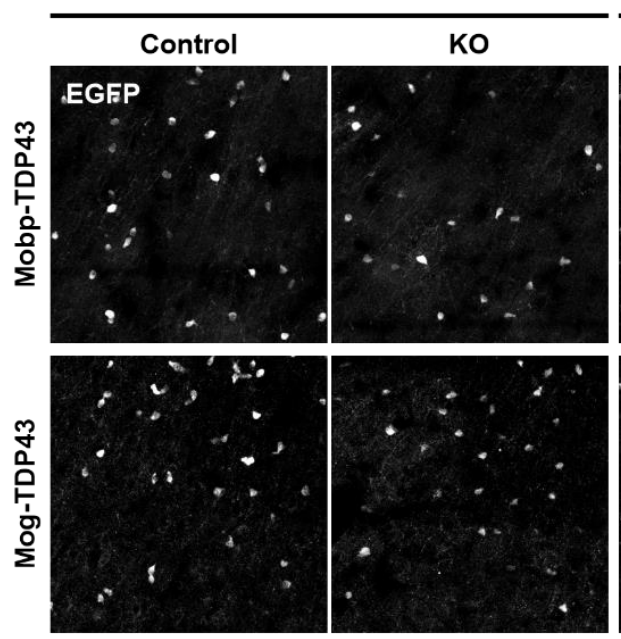

B

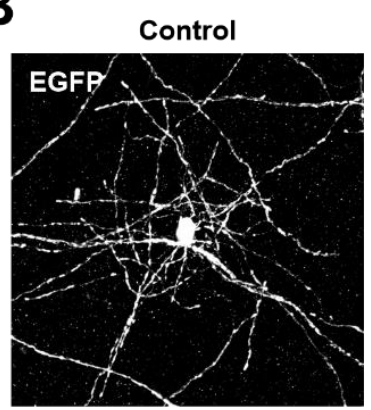

P180 Mobp-TDP43 Ko

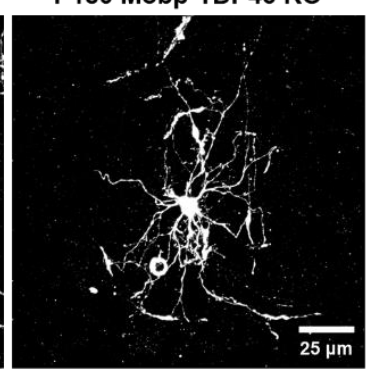

C

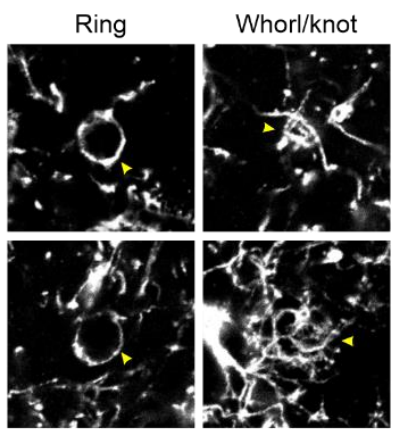

$\mathbf{E}$

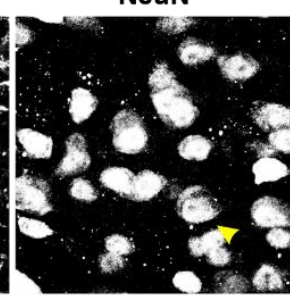

EGFP NeuN
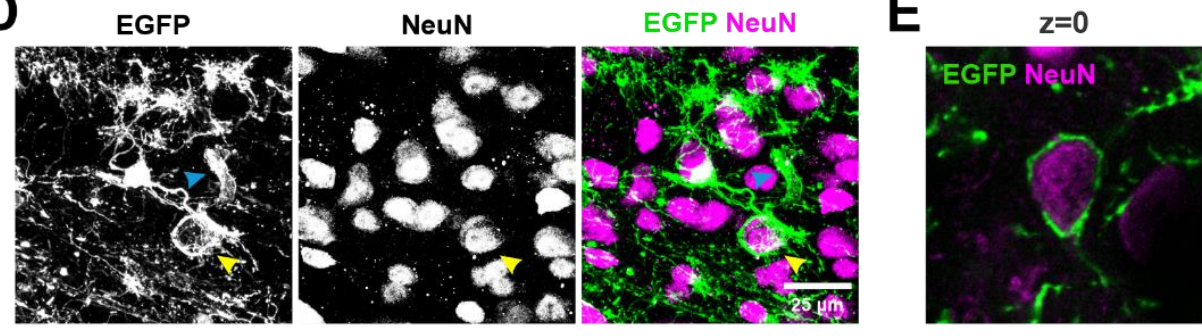

$\mathrm{z}=1.5 \mu \mathrm{m}$
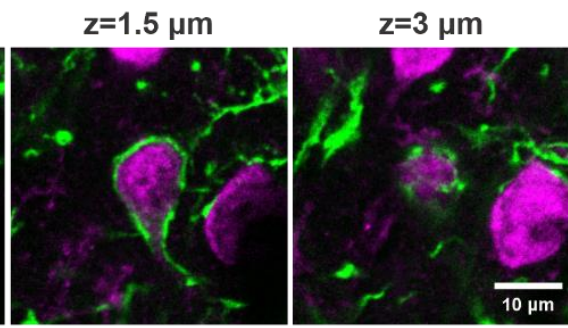

$\mathbf{F}$

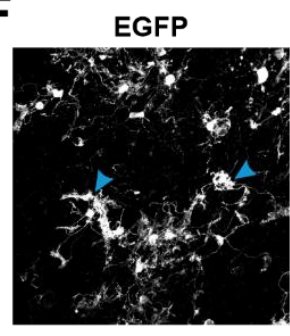

GS-Isolectin

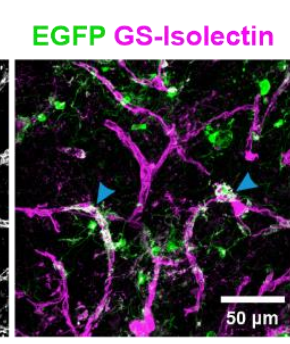

G

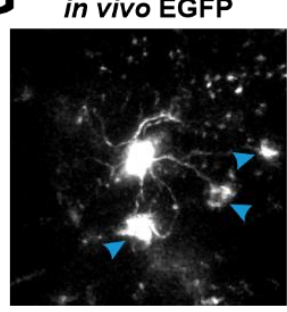

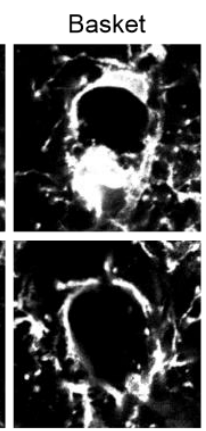

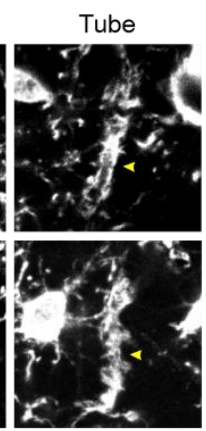

P180
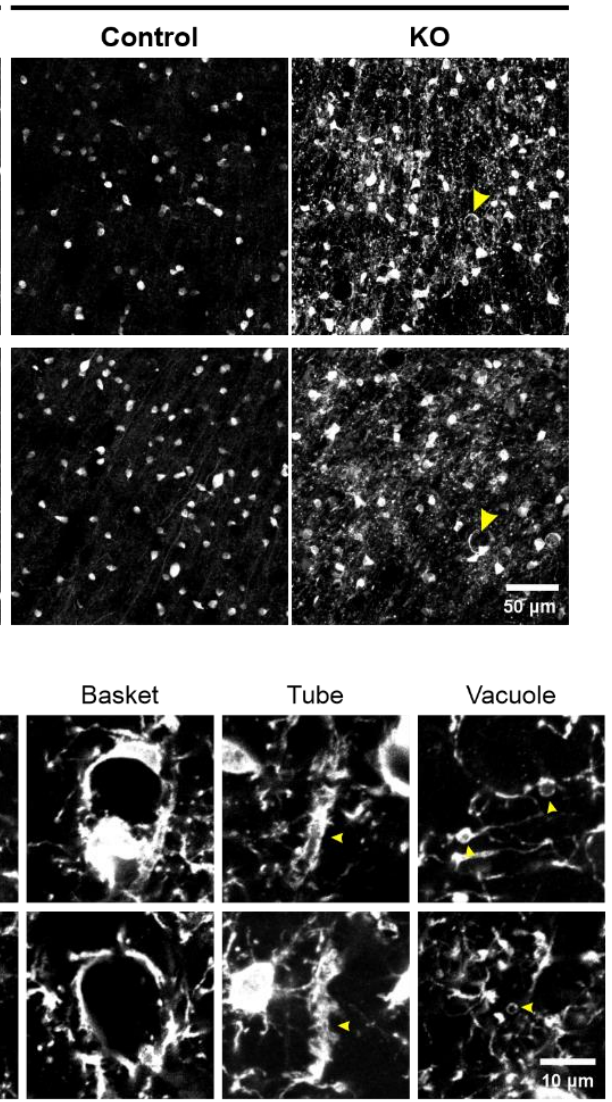

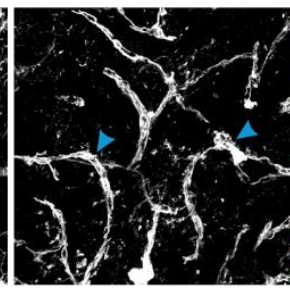

$50 \mu \mathrm{m}$

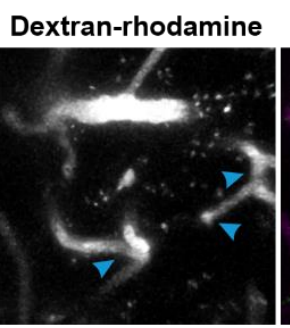

Composite

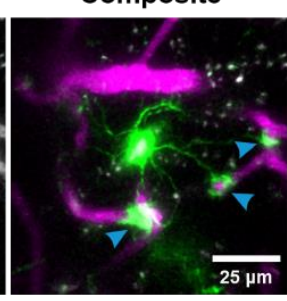

Figure 4 - Oligodendrocytes without TDP-43 undergo aberrant morphological changes and exhibit aberrant

wrapping of non-axonal structures.

A. EGFP images from the motor cortex of Mobp-TDP43-RCE and Mog-TDP43-RCE mouse lines at P30, P90, 
single oligodendrocytes from Control (Mobp-EGFP) and Mobp-TDP43 KO at P180. Scale bar $=25 \mu \mathrm{m}$. C.

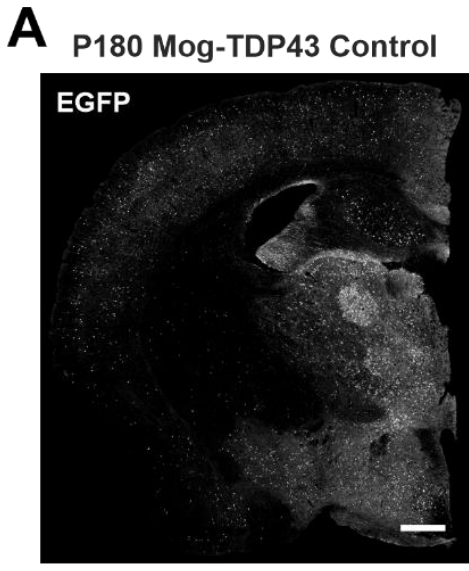
with TDP-43 loss.

Examples of abnormal structures formed by TDP-43 KO oligodendrocytes. Yellow arrowheads point to abnormal structures for each category. Scale bar $=10 \mu \mathrm{m}$. D. Immunostaining of GFP and NeuN in MobpTDP43-RCE KO shows a formation of basket-like EGFP+ structure that ensheaths $\mathrm{NeuN}+$ neuronal cell body (yellow arrowhead). Blue arrowhead points to a tubing-like EGFP+ structure. Scale bar $=25 \mu \mathrm{m}$. E. Optical serial sections representing $1.5 \mu \mathrm{m}$ increments in the z-axis showing wrapping of a $\mathrm{NeuN}+$ neuronal soma by EGFP+ oligodendrocyte processes in Mobp-TDP43-RCE KO at P180. Scale bar $=10 \mu \mathrm{m}$. F. Immunostaining of GFP and GS-Isolectin in Mog-TDP43-RCE KO at P180 shows tight wrapping of the blood vessels by EGFP+ oligodendrocyte processes (blue arrowheads). Scale bar $=50 \mu \mathrm{m}$. G. In vivo imaging of Mobp-TDP43RCE KO mouse after retro-orbital injection of $70 \mathrm{kDa}$ dextran-rhodamine shows wrapping of the capillaries by EGFP+ TDP-43 KO oligodendrocyte. Blue arrows show sites of wrapping. Scale bar $=25 \mu \mathrm{m}$.

Figure 4-figure supplement 1 - Oligodendrocytes undergo dramatic morphological and functional changes

A. Tiled coronal mouse brain section to show that hypertrophic oligodendrocyte changes can be seen throughout the brain at P180. B. EGFP immunoreactivity shows that abnormal oligodendrocyte morphologies can be seen in the optic nerve and spinal cord.

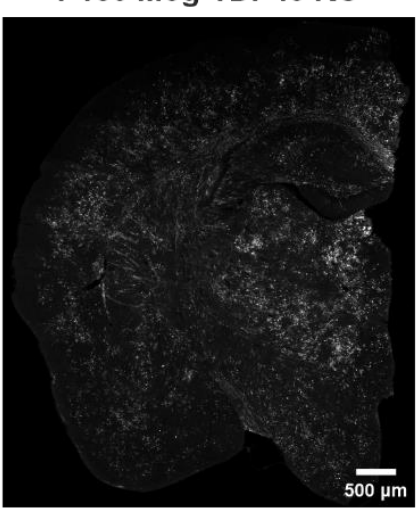

B

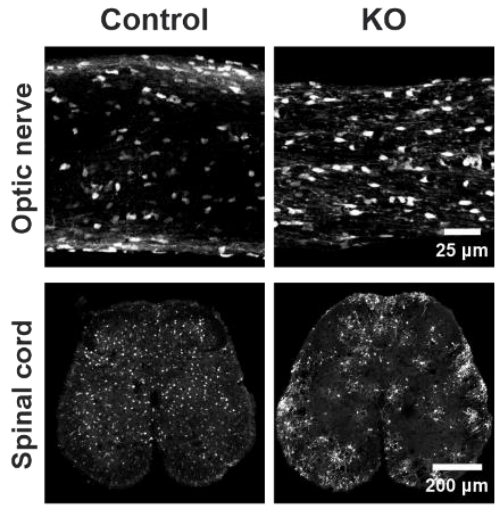



available under aCC-BY-NC-ND 4.0 International license.
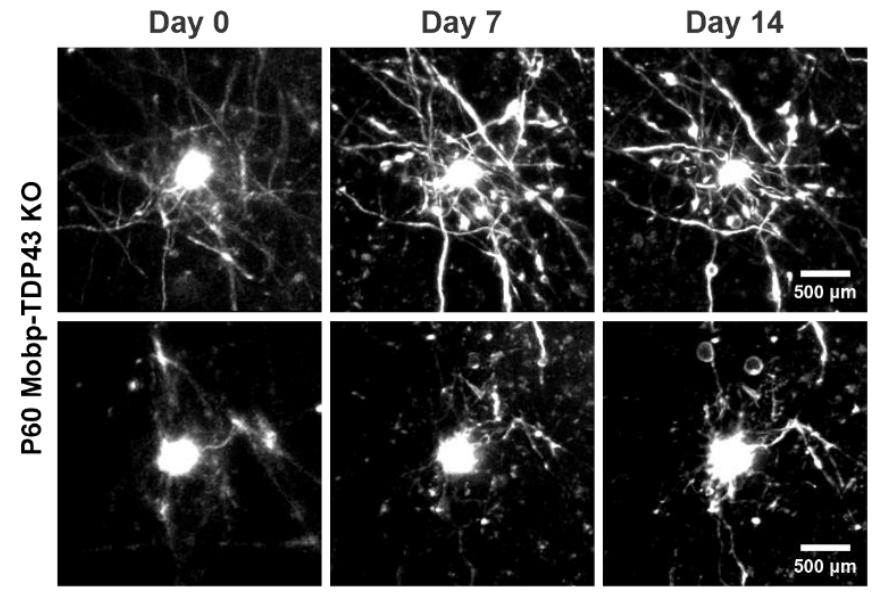

\section{Figure 4-figure supplement 2}

057 Longitudinal two-photon in vivo imaging of Mobp-TDP43 KO oligodendrocytes across 14 days.
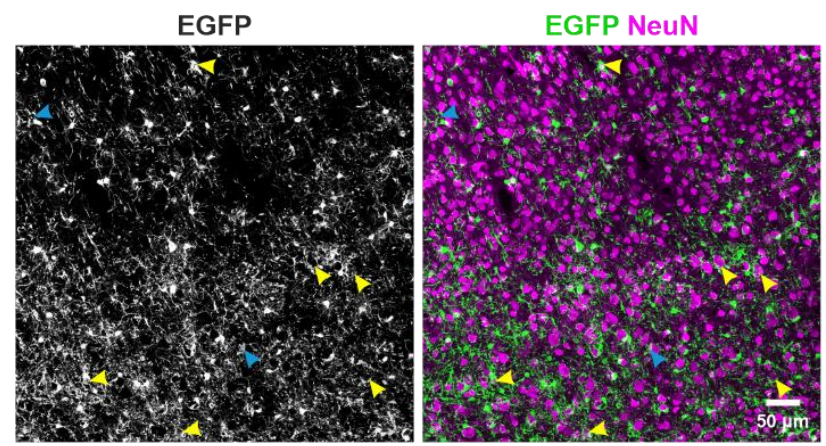

\section{Figure 4-figure supplement 3}

061 Motor cortex of P180 Mobp-TDP43 KO shows that aberrant EGFP structures can be readily identified. Yellow 062 arrowheads indicate neuronal wrapping and blue arrowheads indicate tubing-like structures that resemble 063 blood vessel wrapping.

A

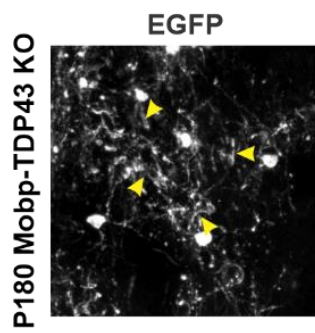

Aquaporin 4

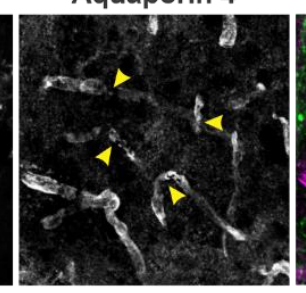

EGFP Aquaporin 4

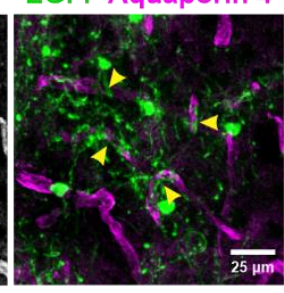

B

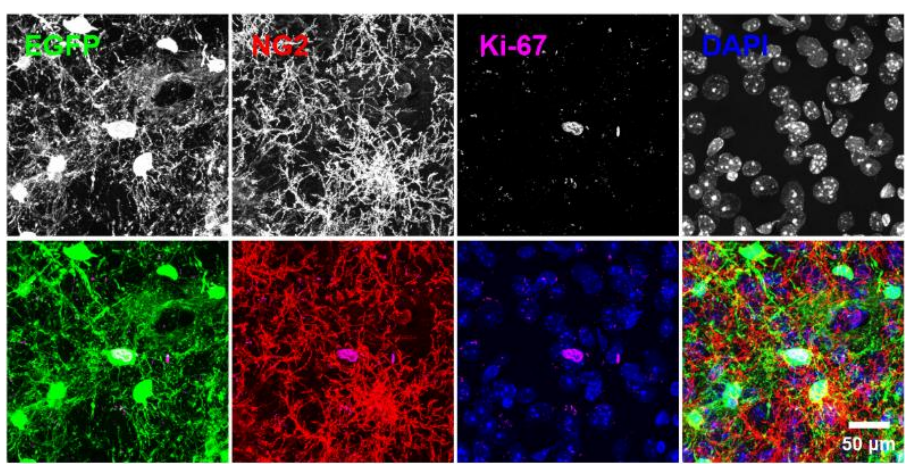


Figure 4-figure supplement 4

A. Immunostaining for aquaporin 4 shows that EGFP+ wrapping displaces aquaporin $4+$ astrocyte endfeet

(yellow arrowheads). B. Ki-67+NG2- oligodendrocytes can be found in P180 Mobp-TDP43 KO.

A

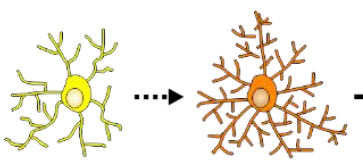

OPC

Premyelinating oligodendrocyte Mobp-iCreER
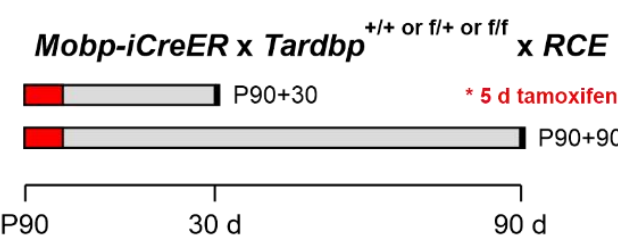

C

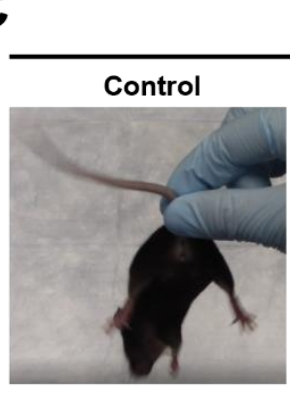

E

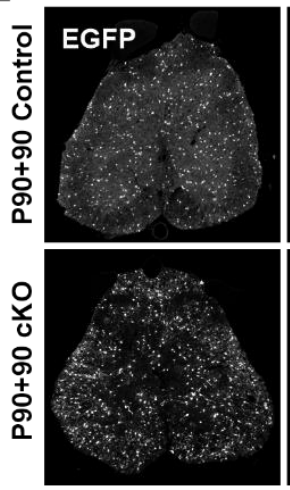

B
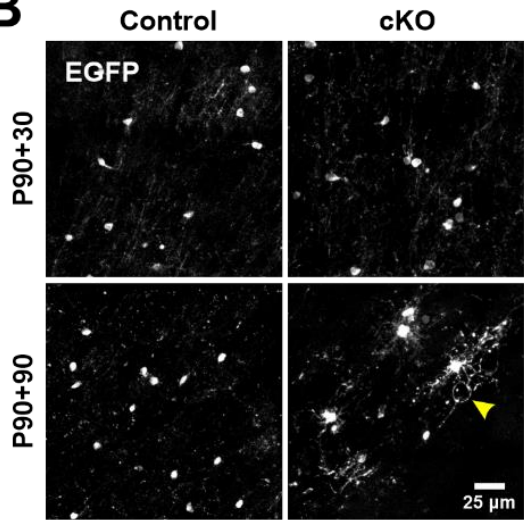

D

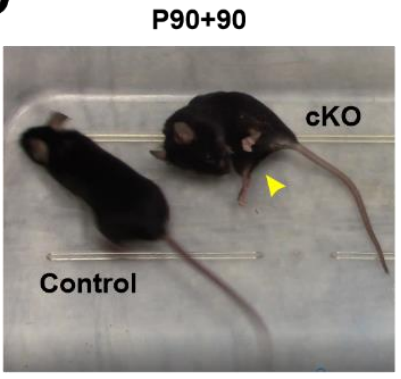

P90+90
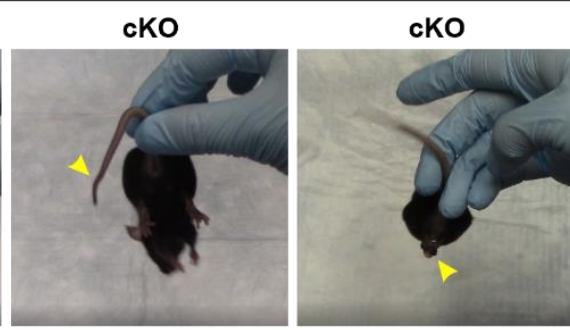

$\mathbf{F}$
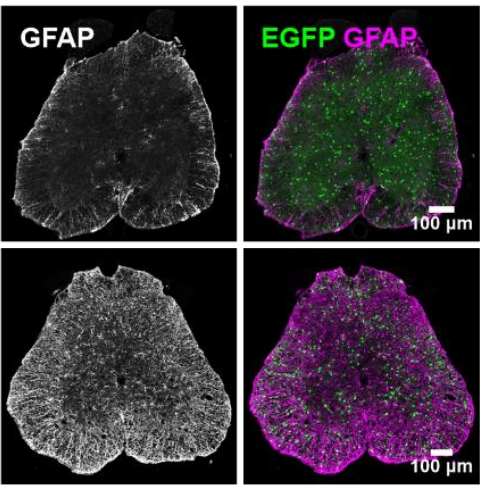

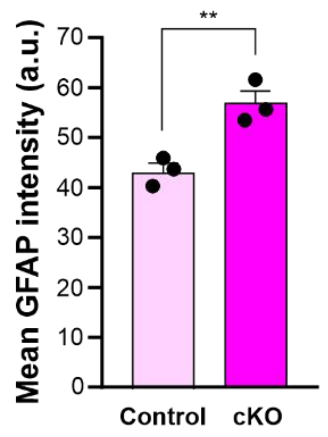

Figure 5 - Adult loss of TDP-43 in oligodendrocytes leads to hindlimb weakness.

A. Mobp-iCreER allows Tardbp deletion at mature oligodendrocytes in the adult CNS. Schematics of CreER activation where tamoxifen is administered for 5 consecutive days at P90. Samples are collected for analyses 30 and 90 days after the last day of tamoxifen injection.

B. EGFP images from Mobp-TDP43-RCE Control and 
cKO at 30 and 90 days after Tardbp deletion. Yellow arrowhead indicates abnormal morphological changes in

C. Examples of limp tail and hindlimb clasping (yellow

arrowheads) in Mobp-TDP43 cKO at P90+90 from Supplementary Video 4. D. Mobp-TDP43 cKO mice develop

hindlimb paralysis at P90+90 (yellow arrowhead). E. Immunostaining for GFP and GFAP in the lumbar spinal cords of Mobp-TDP43-RCE Control and cKO at P90+90 shows global astrogliosis indicated by increased immunoreactivity of GFAP. Scale bar $=100 \mu \mathrm{m}$. F. Quantification of mean GFAP fluorescence intensity (arbitrary unit; a.u.) shows a statistically significant increase in the mean intensity of GFAP in the spinal cord of Mobp-TDP43 cKO (unpaired, two-tailed Student's t-test, ${ }^{* *} \mathrm{p}$-value $=0.0096, \mathrm{n}=3$ ).
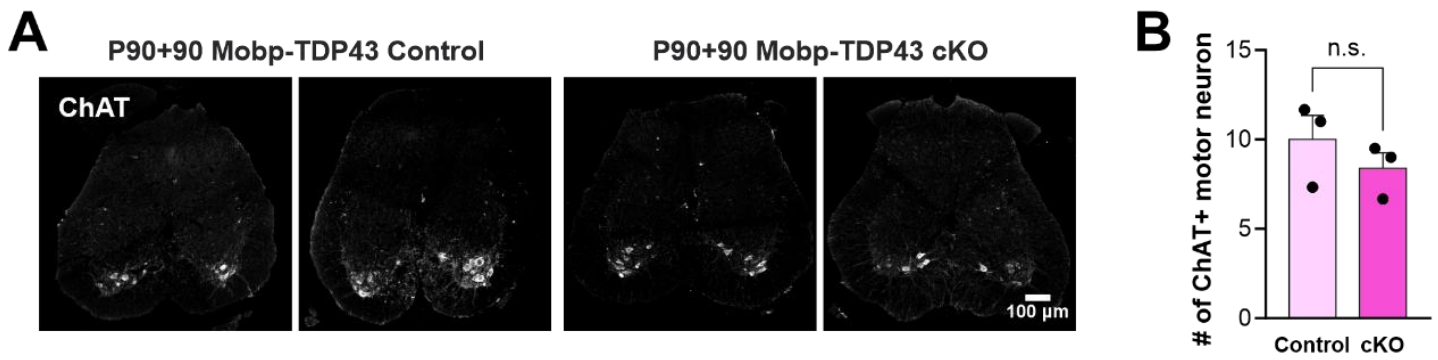

Figure 5-figure supplement 1

08

A. ChAT immunostaining in the spinal cord to visualize motor neurons in the ventral spinal cord. B.

Quantification of the number of ChAT+ motor neurons per $35 \mu \mathrm{m}$ section of the spinal cord (unpaired, twotailed Student's t-test, $\mathrm{n}=3$ ). 
A P30 Mobp-iCre $\times$ Tardbp ${ }^{\mathrm{f} /+ \text { or } \mathrm{f} / \mathrm{f}} \times \mathrm{RCE}$ Mog-iCre $\times \operatorname{Tardbp}^{\mathrm{fl+} \text { or } \mathrm{flf}} \times \mathrm{RCE}$
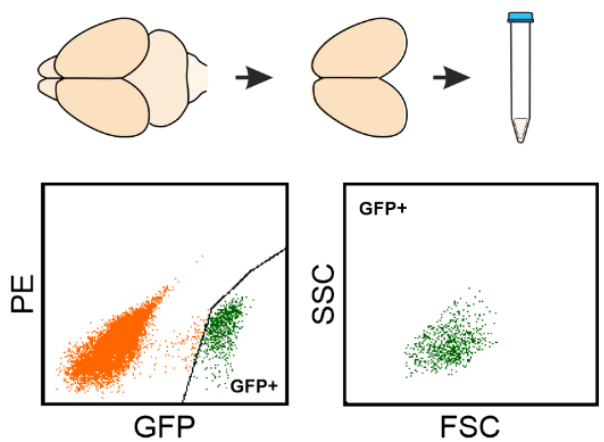

FSC

B

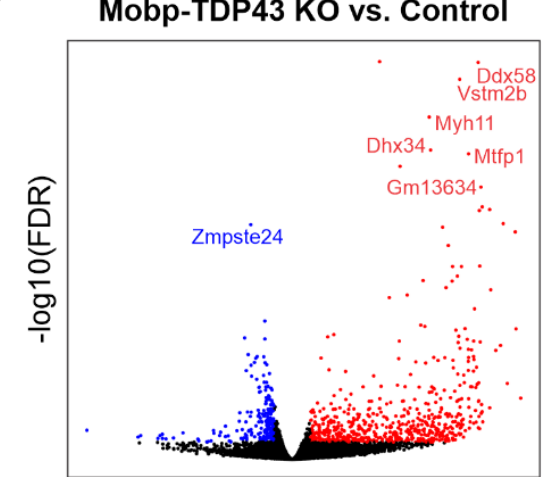

log2(Fold Change)
Mog-TDP43 KO vs. Control

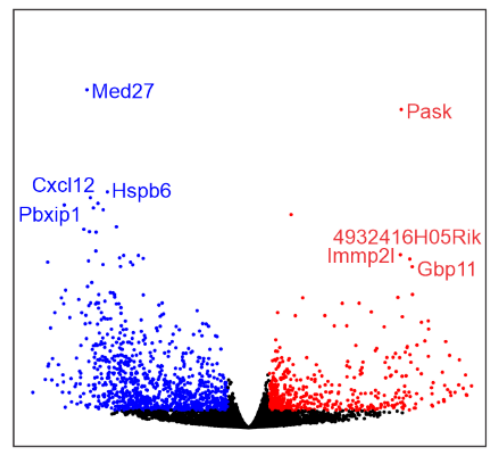

$\log 2$ (Fold Change)

C

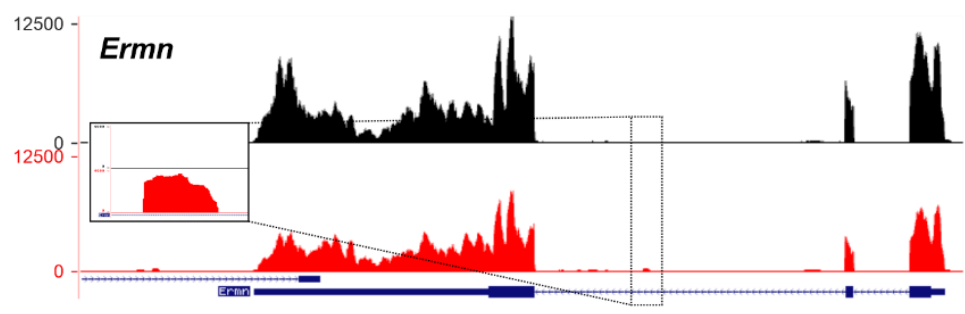

D

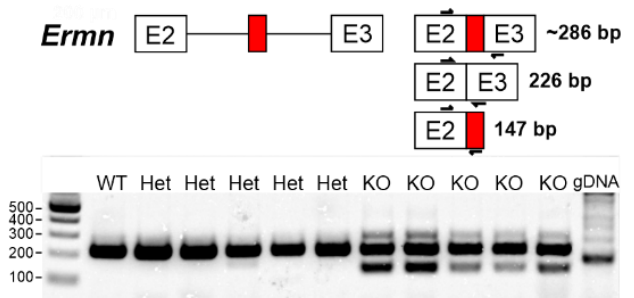

E
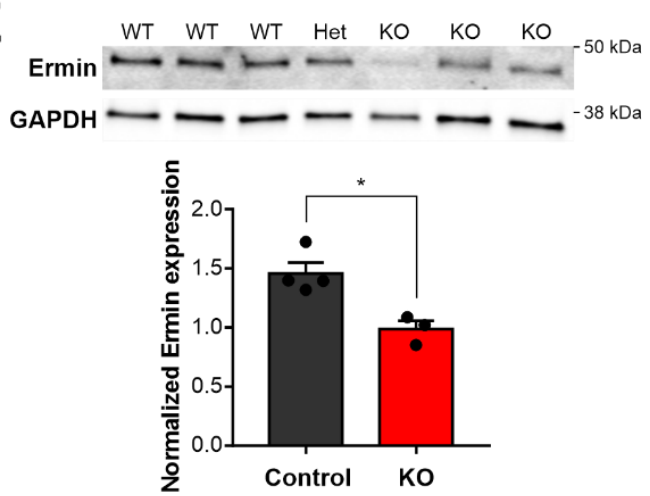

F Genes misspliced in TDP43 KO
\begin{tabular}{|l|l|l|}
\hline Gene & Function & Type \\
\hline Apod & Myelin compaction & Cassette \\
\hline Ermn & Cytoskeleton rearrangement & Cassette \\
\hline Sema6d & Oligodendrogenesis & Cassette \\
\hline Exoc3 & Oligodendrogenesis; oligodendrocyte membrane formation & Exon extension \\
\hline Erbin & Neuregulin 1 signaling; required for remyelination & Exon extension \\
\hline Ncam1 & Neural cell adhesion molecule & Alternative splicing \\
\hline Sort1 & Neuronal survival; progranulin (PGRN) metabolism & Alternative splicing \\
\hline Hmgcs1 & Oligodendrogenesis; myelin gene expression & Alternative splicing \\
\hline
\end{tabular}

Figure 6 - TDP-43 maintains oligodendrocyte transcriptional integrity by suppressing cryptic exon incorporation in key oligodendrocyte genes.

A. Bulk RNA-Seq was performed with FACS isolated EGFP+ oligodendrocytes from P30 Mobp-TDP43-RCE and Mog-TDP43-RCE cortices. B. Volcano plots comparing KO to Control in Mobp-TDP43 and Mog-TDP43 mouse lines showing statistically significantly differentially expressed genes (Fold Change $>1$, adjusted pvalue $(F D R)<0.05)$. Blue dots indicate downregulated genes whereas red dots indicate upregulated genes with TDP-43 KO. C. Visualization of the cryptic exon located in Ermn. Gene annotation is shown on the bottom, labeling exons (thick) and introns (thin). Bulk RNA-Seq reads from Control and KO oligodendrocytes from both 
of Ermn is magnified to highlight the difference. D. RT-PCR validation of cryptic exon incorporation in Ermn in mouse whole brain tissue from Mog-TDP43 Control and KO. Three primers were used to identify 1) normal transcript (226 bp), 2) cryptic exon incorporated transcript (286 bp), and 3) the presence of cryptic exon (147 bp). Only the KO samples showed bands at $147 \mathrm{bp}$ and $286 \mathrm{bp}$ that represent cryptic exon incorporation into Ermn mRNA. E. Western blotting assay to quantify the amount of Ermin protein in Mog-TDP43 Control and KO brains shows that Mog-TDP43 KO brains have a significantly decreased amount of Ermin protein (unpaired, two-tailed Student's t-test, * $p$-value $=0.0119, n=4,3)$. F. Table of genes that are misspliced in oligodendrocytes with loss of TDP-43. Cassette indicates incorporation of a non-conserved, novel cryptic exon whereas alternative splicing means usage of alternative, conserved exons. Exon extension indicates that the intronic sequence following an exon was incorporated into mature mRNA and became part of the exonic sequence.

\begin{tabular}{|c|c|c|c|}
\hline $\begin{array}{c}\text { Mog-TDP43 Control } \\
\text { vs. Mobp-TDP43 Control }\end{array}$ & $\begin{array}{c}\text { Mog-TDP43 Control } \\
\text { vs. Mog-TDP43 KO }\end{array}$ & $\begin{array}{c}\text { Mobp-TDP43 Control } \\
\text { vs. Mobp-TDP43 KO }\end{array}$ & Control vs. KO \\
\hline 4,436 & 1,820 & 1,032 & 920 \\
\hline
\end{tabular}

\section{Figure 6-figure supplement 1}

Number of genes that are statistically significantly differentially expressed between different genotypes (FDR < 
bioRxiv preprint doi: https://doi.org/10.1101/2021.11.09.467933; this version posted November 9, 2021. The copyright holder for this preprint (which was not certified by peer review) is the author/funder, who has granted bioRxiv a license to display the preprint in perpetuity. It is made available under aCC-BY-NC-ND 4.0 International license.

Mobp-TDP43 Control vs. KO

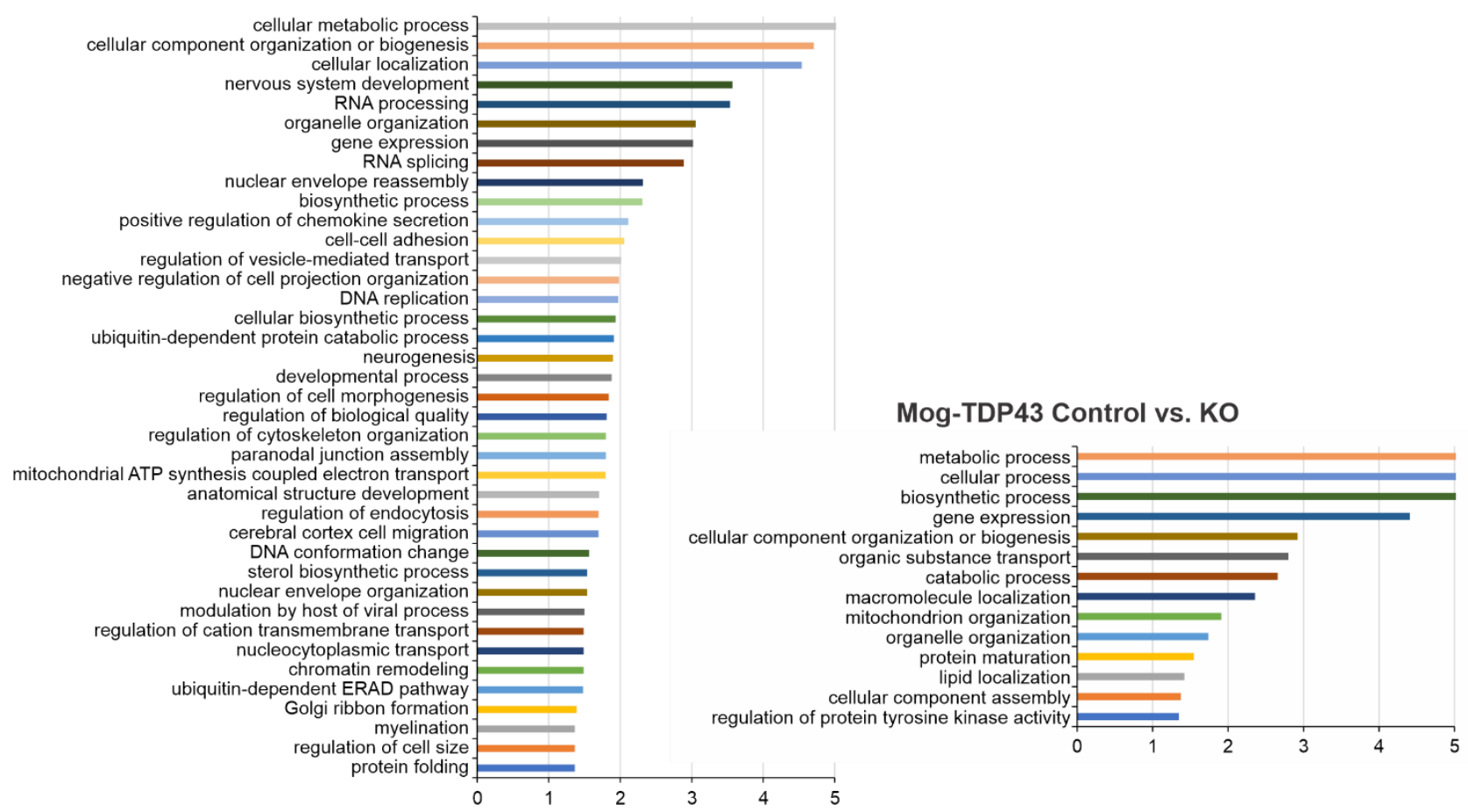

118 Figure 6-figure supplement 2

Gene ontology (GO) analysis from differentially expressed genes shows that Mobp-TDP43 KO and Mog-
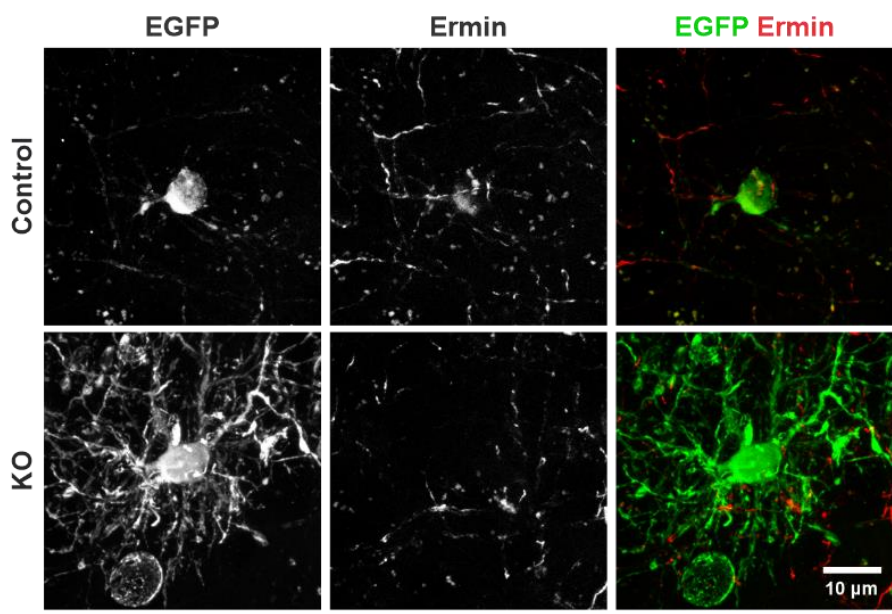

Figure 6-figure supplement 3

124 Immunostaining for Ermin shows that $\mathrm{KO}$ oligodendrocytes have reduced cell body expression of Ermin protein

compared to the Control. 


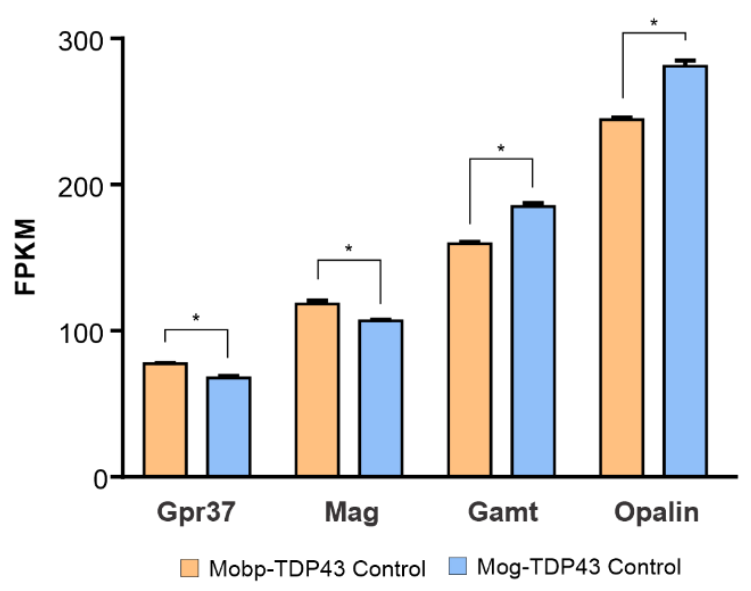

Figure 6-figure supplement 4

Fragments per kilobase of exon per million mapped fragments (FPKM) of Gpr37, Mag, Gamt, and Opalin in

Mobp-TDP43 Control and Mog-TDP43 Control from bulk RNA-Seq in Figure 6. Unpaired, two-tailed Student's

t-test was used to determine statistical significance at $p$-value $<0.05$.

Supplementary Video 1 - Video of Mobp-TDP43 Control and KO mice where Mobp-TDP43 KO mice undergo spontaneous seizures and reduced threshold for seizures.

Supplementary Video 2 - Longitudinal in vivo imaging of Mobp-TDP43 KO oligodendrocytes.

Supplementary Video 3-3D video of EGFP+ KO oligodendrocyte that wrap around NeuN+ neuronal somata. exhibit hindlimb paralysis, limp tail, and hindlimb clasping.

Supplementary Data - Differential gene expression Excel file of bulk RNA-Seq. 